Article

\title{
An Averaged-Value Model of an Asymmetrical Hybrid Multi-Level Rectifier
}

\author{
Salvatore Foti ${ }^{1, *} \mathbb{C}$, Giacomo Scelba $^{2} \mathbb{D}$, Antonio Testa ${ }^{1}$ and Angelo Sciacca ${ }^{3}$ \\ 1 DI, University of Messina, 98122 Messina, Italy; atesta@unime.it \\ 2 DIEEI, University of Catania, 95131 Catania, Italy; giacomo.scelba@dieei.unict.it \\ 3 ST Microelectronics, I-95121 Catania, Italy; angelo.sciacca@st.com \\ * Correspondence: sfoti@unime.it; Tel.: +39-3206487898
}

Received: 30 December 2018; Accepted: 6 February 2019; Published: 13 February 2019 updates

\begin{abstract}
The development and the validation of an averaged-value mathematical model of an asymmetrical hybrid multi-level rectifier is presented in this work. Such a rectifier is composed of a three-level T-type unidirectional rectifier and of a two-level inverter connected to an open-end winding electrical machine. The T-type rectifier, which supplies the load, operates at quite a low switching frequency in order to minimize inverter power losses. The two-level inverter is instead driven by a standard sinusoidal pulse width modulation (SPWM) technique to suitably shape the input current. The two-level inverter also plays a key role in actively balancing the voltage across the DC bus capacitors of the T-type rectifier, making unnecessary additional circuits. Such an asymmetrical structure achieves a higher efficiency compared to conventional PWM multilevel rectifiers, even considering extra power losses due to the auxiliary inverter. In spite of its advantageous features, the asymmetrical hybrid multi-level rectifier topology is a quite complex system, which requires suitable mathematical tools for control and optimization purposes. This paper intends to be a step in this direction by deriving an averaged-value mathematical model of the whole system, which is validated through comparison with other modeling approaches and experimental results. The paper is mainly focused on applications in the field of electrical power generation; however, the converter structure can be also exploited in a variety of grid-connected applications by replacing the generator with a transformer featuring an open-end secondary winding arrangement.
\end{abstract}

Keywords: electrical drives; energy saving; multilevel power converters; permanent magnet synchronous generator; open-end winding configuration; voltage balancing; power factor

\section{Introduction}

Multi-level converters have proved in the last decades to be a viable alternative to conventional topologies in medium-voltage, high-power, industrial applications, but today, their field of applications is rapidly spreading toward low-power and low-voltage ranges. Main advantages of multi-level converters are basically those of an improved harmonic content of $\mathrm{AC}$ voltages and currents and of a reduction of power switch voltage ratings [1,2], the main drawback being a greater complexity. Open-winding (OW) configurations, consisting of an AC machine fed by two power converters [3-6], can be deemed as a special kind of multi-level converter [7]. Different configurations, control schemes, and modulation techniques dealing with OW systems have been discussed in the literature [8-10]. Some OW configurations embedding multi-level converters have also been recently developed [11-13]. Among them, a high efficiency asymmetrical hybrid multilevel inverter for motor drives has been presented and analyzed in [12] featuring a particular asymmetrical structure where two different kinds of converters are connected at the two sides of an OW AC machine with different functions. Specifically, a main multilevel converter supplies the load, and an auxiliary two-level inverter acts as 
an active power filter. Such an approach has also been used in [13] to realize an asymmetrical hybrid unidirectional T-type rectifier (AHUTR) for gen-set applications, tailored around an open-end winding permanent magnet synchronous generator (PMSG), as shown in Figure 1. According to the AHUTR topology, the open-end winding PMSG on one side supplies the electrical load through the main converter, a T-type rectifier (TTR), also commonly known as a Vienna rectifier, and on the other side, it is connected to an auxiliary two-level inverter (TLI). The main converter processes the whole power delivered to the load, and thus, it is operated at the fundamental frequency in order to minimize the switching power losses. The TLI is instead driven by a high switching frequency PWM technique to suitably shape the phase currents. Therefore, a stable output DC voltage and almost sinusoidal input currents are obtained, achieving a higher efficiency than comparable conventional PWM rectifiers [12]. The AHUTR structure is also of general applicability, being exploitable in grid-connected applications by replacing the generator with a transformer featuring an open-end secondary winding, as shown in Figure 1, but it is more complex than conventional rectifiers, requiring suitable mathematical tools for control and optimization purposes. The aim of this work is thus to provide an essential tool for the design of the control system of an AHUTR by developing an averaged-value model $(\mathrm{AVM})$ of the system. In general, averaged-value techniques approximate the model of a switching converter to a continuous system by considering the values taken by the variables along a switching period as constant. They are useful when designing and testing control algorithms, as well as to develop efficiency optimization techniques, because a high frequency dynamic analysis is not required, differently than power circuits and filters design. Specifically, an AHUTR AVM has been developed with the aim to support the design of effective solutions to maximize system efficiency, to provide a stable DC output voltage, to cancel low-order undesired harmonics from the phase currents, to equalize the Vienna rectifier DC bus capacitor voltages, and to control the TLI DC bus voltage. Furthermore, the developed model is valuable in tuning voltage and current regulators.

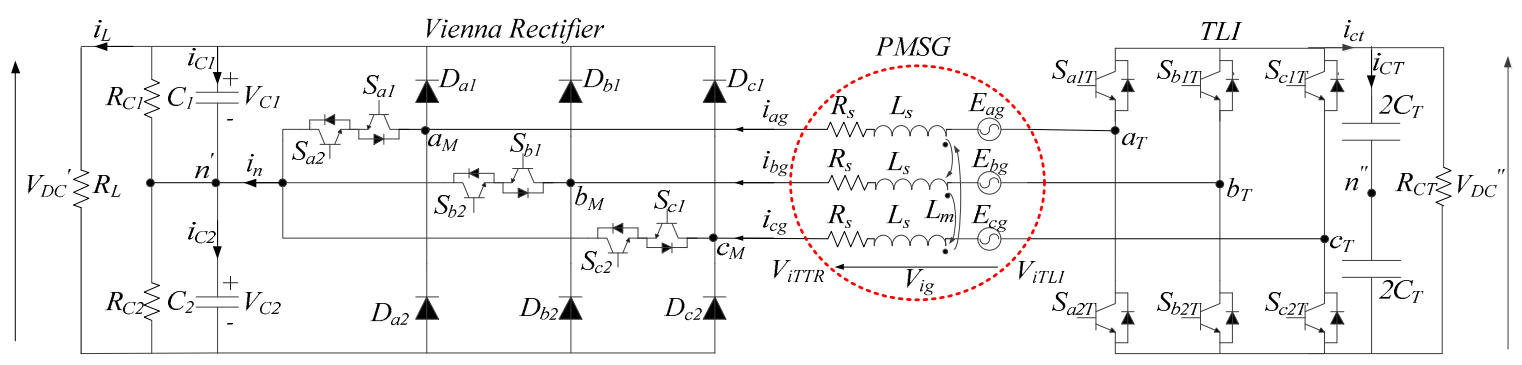

(a)

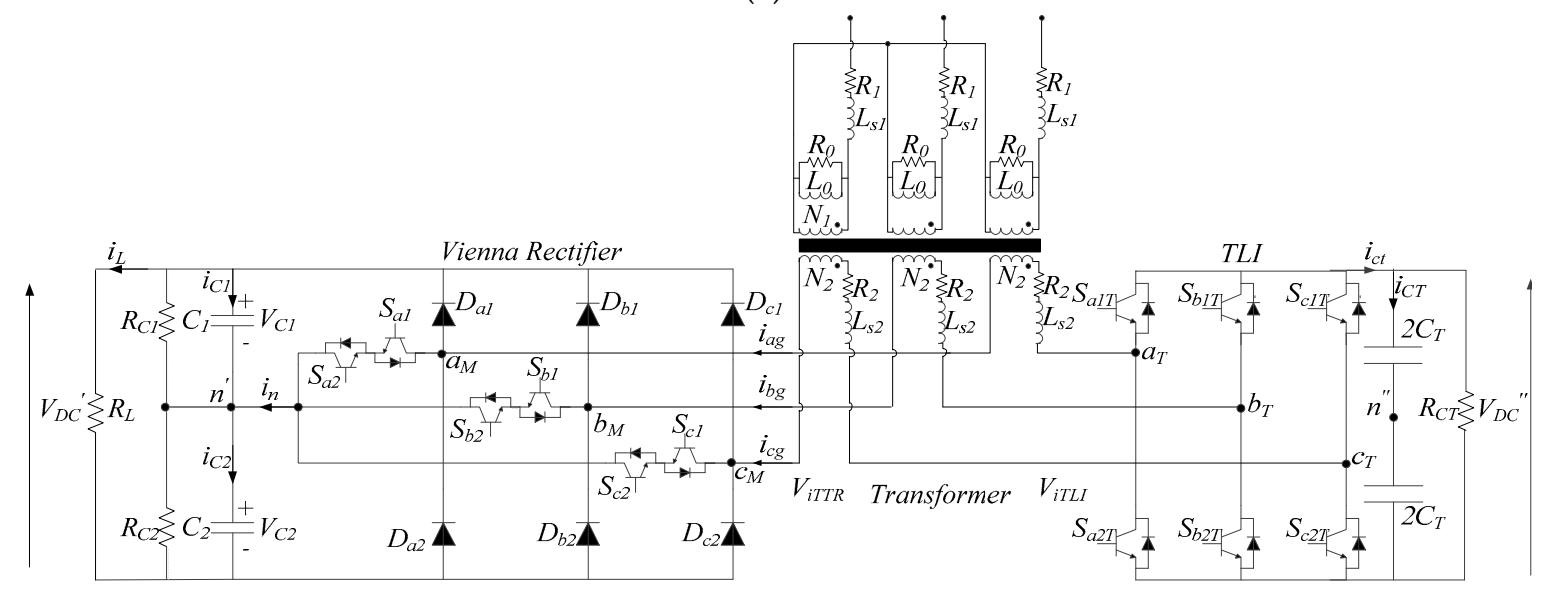

(b)

Figure 1. AHUTR for electrical power generation (a) and grid-connected (b) applications. 


\section{Asymmetrical Hybrid Unidirectional T-Type Rectifier}

According to Figure 1, an AHUTR supplies the load through a Vienna rectifier switching at fundamental frequency. In electricity generation applications, this rectifier is connected to one end of an open winding electrical generator, very often a PMSG. For grid-connected applications, the electrical generator is replaced by a transformer with an open-end secondary winding. While remarkably reducing the switching power losses, low switching frequency operations would, however, produce highly distorted phase currents. This is prevented by an active power filter based on a conventional TLI, which is connected to the other end of the electrical machine winding. Such an inverter features a lower DC bus voltage compared to the Vienna rectifier and exploits a floating capacitor to reduce the complexity of the system and to prevent the occurrence of zero sequence currents [11-13]. The efficiency of the Vienna rectifier can be increased by using low on-state voltage drop power devices, thus optimizing the design of this converter for low conduction power losses. On the other hand, the design of the TLI can be optimized for high switching frequency operation, by using fast power devices with lower voltage ratings. A key feature of the AHUTR topology is that the voltages of the two Vienna rectifier DC bus capacitors can be independently regulated through the TLI, thus making unnecessary additional power converters or special PWM strategies.

In the AHUTR topology, three bidirectional switches $S_{i j},(i=a, b, c$ and $j=1,2)$ are connected between the midpoint $n^{\prime}$ of the Vienna rectifier and the rectifier poles [14]. The generic $i$-phase voltage $V_{\text {iTTR }}$ between the rectifier input terminal $i_{M}$ and the mid-point $n^{\prime \prime}$ of the Vienna rectifier DC bus is given by

$$
V_{i T T R}=\frac{l_{i}^{\prime}-1}{2} V_{D C}{ }^{\prime}, l_{i}^{\prime}=0,1,2
$$

where $V_{D C}$ is the DC bus voltage. Hence, three different levels can be taken by the Vienna rectifier input voltage, namely: $-V_{D C^{\prime}} / 2, V_{D C}{ }^{\prime} / 2$, and 0 , according to the rectifier $i$-pole state $l_{i}{ }^{\prime}$.

On the TLI side, the voltage between the TLI $i$-phase output terminal $i_{T}$ and the mid-point $n^{\prime}$ of the TLI DC bus is given by:

$$
V_{i T L I}=\frac{2 l_{i}^{\prime \prime}-1}{2} V_{D C^{\prime \prime}}, l_{i}^{\prime \prime}=0,1
$$

providing two voltage levels, namely, $-V_{D C} C^{\prime \prime} / 2$ and $V_{D C} C^{\prime \prime} / 2$, according to the inverter $i$-pole state $l_{i}^{\prime \prime}$.

The voltage across a phase winding is given by

$$
V_{i g}=V_{i T T R}-V_{i T L I}-V_{n^{\prime} n^{\prime \prime}}=\frac{l_{i}^{\prime \prime}-1}{2} V_{D C^{\prime}}-\frac{2 l_{i}^{\prime \prime}-1}{2} V_{D C^{\prime \prime}}-V_{n^{\prime} n^{\prime \prime}}
$$

where $V_{D C}{ }^{\prime}$ and $V_{D C}$ " are the DC bus voltages of the Vienna rectifier and the TLI, respectively, and $V_{n^{\prime} n^{\prime \prime}}$ is the voltage between the mid points $n^{\prime}$ and $n^{\prime \prime}$ of the two DC buses, which can be expressed as

$$
V_{n^{\prime} n^{\prime \prime}}=\frac{1}{3}\left(V_{a T T R}+V_{b T T R}+V_{c T T R}\right)-\frac{1}{3}\left(V_{a T L I}+V_{b T L I}+V_{c T L I}\right) .
$$

According to (2) and (3), the OW structure of Figure 1, featuring twelve power switches, is equivalent to a six-level neutral point clamped (NPC) or flying capacitor (FC) converter, which would, however, encompass thirty power switches [12]. As shown in Figure 2, the AHUTR requires a complex control system to suitably coordinate the operations of the two converters in order to regulate the DC output voltage, to cancel low-order harmonics from phase currents, to equalize the Vienna rectifier DC bus capacitor voltages, and to control the TLI DC bus voltage $[14,15]$. 


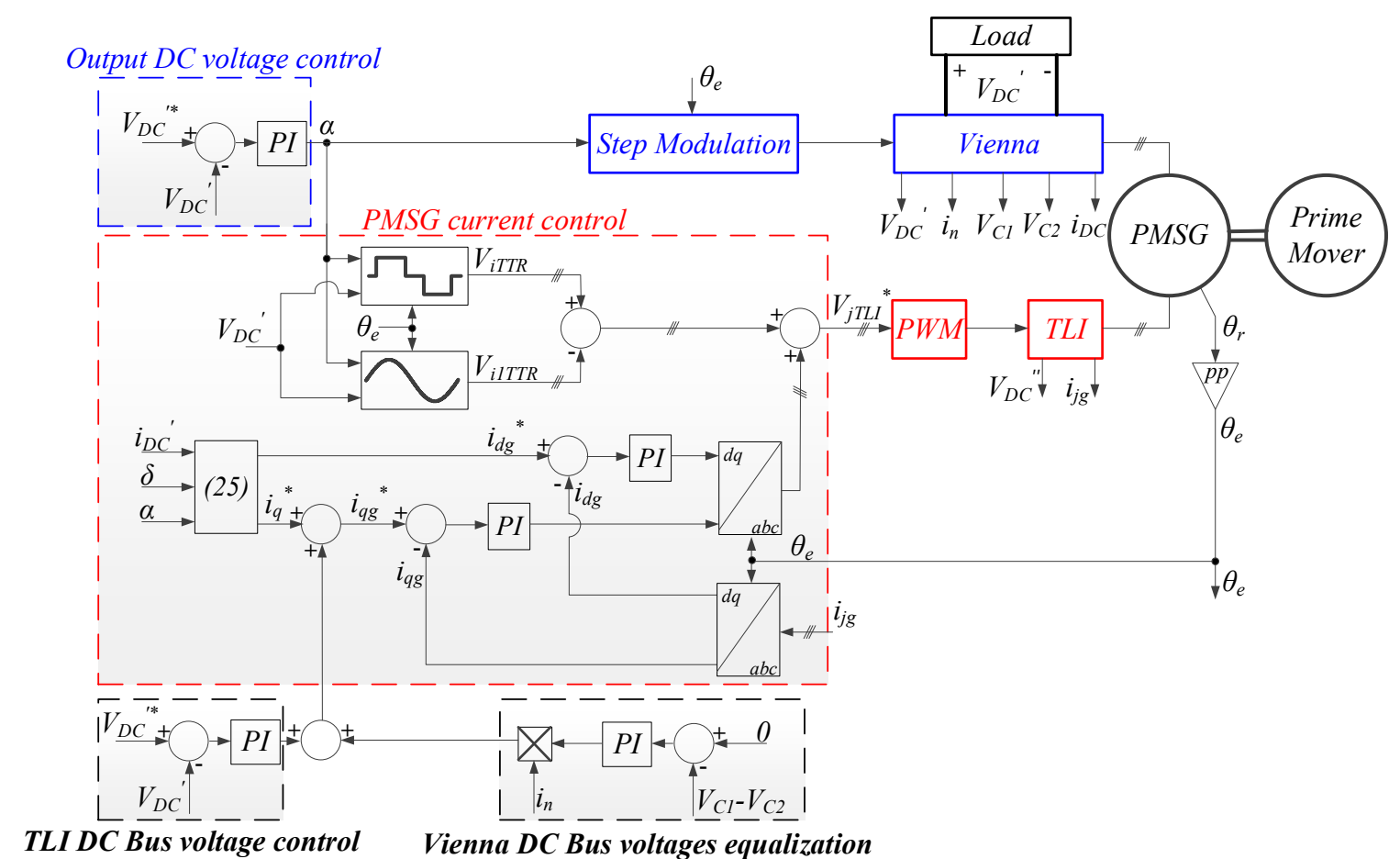

Figure 2. Block diagram of the control system of the AHUTR for electrical power generation applications.

\section{Averaged-value Model of the System}

The averaged-value mathematical model of the system includes three sub-models: of the electrical machine, of the Vienna rectifier, and of the TLI.

\subsection{Open-Winding PMSG Model}

It is assumed that the stator windings produce sinusoidal magnetomotive forces; moreover, effects of the saturation of the magnetic core are neglected. Under these assumptions, the surface-mounted PMSG model in an orthogonal $q d$ reference frame synchronous to the rotor flux is given by the following sets of Equations:

$$
\begin{gathered}
V_{q s}=R_{s} i_{q s}+\frac{d}{d t} \lambda_{q s}+\omega_{r e} \lambda_{d s} \\
V_{d s}=R_{s} i_{d s}+\frac{d}{d t} \lambda_{d s}-\omega_{r e} \lambda_{q s} \\
\lambda_{q s}=L_{s} i_{q s} \\
\lambda_{d s}=L_{s} i_{d s}+\lambda_{p m} \\
T_{e}=\frac{3}{2} p p\left(\lambda_{d s} i_{q s}-\lambda_{q s} i_{d s}\right) \\
T_{e}-T_{L}=J \frac{d}{d t} \omega_{r}+F \omega_{r}
\end{gathered}
$$

where $i_{q s}, i_{d s}, V_{q s}, V_{d s}, \lambda_{q s}$, and $\lambda_{d s}$ are the components of stator current, voltage, and flux in the $q d$ axis; $L_{s}$ is the stator inductance; $\lambda_{p m}$ is the linkage flux of permanent magnets; $T_{e}$ is the electromagnetic torque; $J$ is the total mechanical inertia; $F$ is the rotor friction; $\omega_{r e}=p p \omega_{r}$ is the rotor speed; and $p p$ is the amount of pole pairs. The rotational terms $\omega_{r e} \lambda_{d s}$ and $\omega_{r e} \lambda_{q s}$ account for the $q d$ axis back-emf $E_{q}$ and $E_{d}$, respectively.

The averaged-value PMSG phase voltage $V_{i g}$ is obtained as the difference between the fundamental harmonic $\bar{V}_{i T T R}$ of the Vienna rectifier input voltage and the fundamental harmonic $\bar{V}_{i T L I}$ of the TLI output voltage. The voltage $V_{n^{\prime} n^{\prime \prime}}$ between the mid points of the two DC buses can be neglected for averaged-value analysis, since it only includes high frequency harmonics [13]. 
PMSG phase voltages can be expressed in a $q d$ synchronous reference frame to the back-EMF vector as a function of $q d$ components of voltages $\bar{V}_{i T T R}$ and $\bar{V}_{i T L I}$ by:

$$
\begin{gathered}
\left|\begin{array}{c}
\bar{V}_{q T T R} \\
\bar{V}_{d T T R}
\end{array}\right|=\frac{2}{3}\left|\begin{array}{ccc}
\cos \left(\omega_{r e} t\right) & \cos \left(\omega_{r e} t-\frac{2}{3} \pi\right) & \cos \left(\omega_{r e} t+\frac{2}{3} \pi\right) \\
\sin \left(\omega_{r e} t\right) & \sin \left(\omega_{r e} t-\frac{2}{3} \pi\right) & \sin \left(\omega_{r e} t+\frac{2}{3} \pi\right) \\
\frac{1}{2} & \frac{1}{2} & \frac{1}{2}
\end{array}\right|\left|\begin{array}{c}
\bar{V}_{a T T R} \\
\bar{V}_{b T T R} \\
\bar{V}_{c T T R}
\end{array}\right| \\
\left|\begin{array}{c}
\bar{V}_{q T L I} \\
\bar{V}_{d T L I}
\end{array}\right|=\frac{2}{3} \times\left|\begin{array}{ccc}
\cos \left(\omega_{r e} t\right) & \cos \left(\omega_{r e} t-\frac{2}{3} \pi\right) & \cos \left(\omega_{r e} t+\frac{2}{3} \pi\right) \\
\sin \left(\omega_{r e} t\right) & \sin \left(\omega_{r e} t-\frac{2}{3} \pi\right) & \sin \left(\omega_{r e} t+\frac{2}{3} \pi\right) \\
\frac{1}{2} & \frac{1}{2} & \frac{1}{2}
\end{array}\right| \times\left|\begin{array}{c}
\bar{V}_{a T L I} \\
\bar{V}_{b T L I} \\
\bar{V}_{c T L I}
\end{array}\right| \\
\bar{V}_{q g}=\bar{V}_{q T T R}-\bar{V}_{q T L I}, \bar{V}_{d g}=\bar{V}_{d T T R}-\bar{V}_{d T L I}
\end{gathered}
$$

A block scheme of the PMSG model is shown in Figure 3.

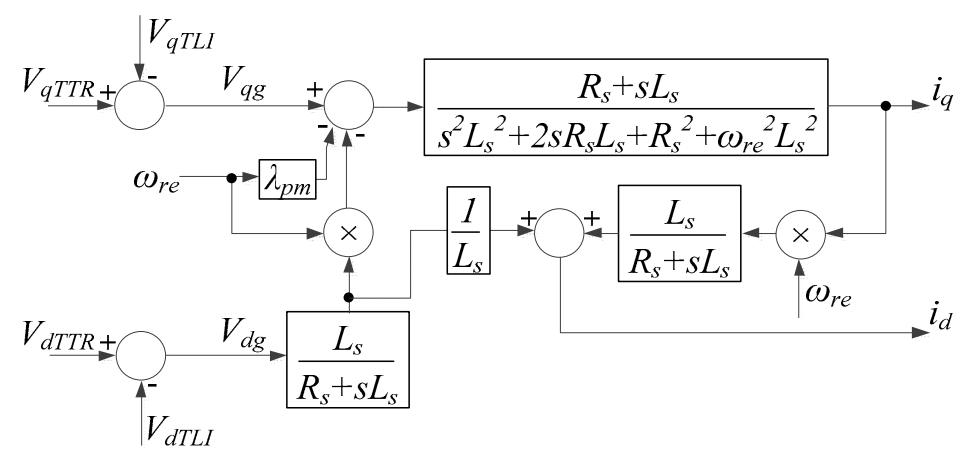

Figure 3. Block scheme of the permanent magnet synchronous generator (PMSG) model.

Similarly, a three-phase open secondary winding transformer (OSWT) can be modeled in an orthogonal $q d$ reference frame synchronous to the primary voltage vector according to:

$$
\begin{gathered}
V_{q 1}=R_{1} i_{q 1}+\frac{d}{d t} \lambda_{q 1}+\omega_{e} \lambda_{d 1} \\
V_{d 1}=R_{1} i_{d 1}+\frac{d}{d t} \lambda_{d 1}-\omega_{e} \lambda_{q 1} \\
V_{q 2}=R_{2} i_{q 2}+\frac{d}{d t} \lambda_{q 2}+\omega_{e} \lambda_{d 2} \\
V_{d 2}=R_{2} i_{d 2}+\frac{d}{d t} \lambda_{d 2}-\omega_{e} \lambda_{q 2} \\
\lambda_{q 1}=L_{s 1} i_{q 1}+L_{m} i_{q 2} \\
\lambda_{d 1}=L_{s 1} i_{d 1}+L_{m} i_{d 2} \\
\lambda_{q 2}=L_{s 2} i_{q 2}+L_{m} i_{q 1} \\
\lambda_{d 2}=L_{s 2} i_{d 2}+L_{m} i_{d 1} \\
L_{s 1}=L_{l 1}+L_{m} \\
L_{s 2}=L_{l 2}+L_{m}
\end{gathered}
$$

where $i_{q 1}, i_{d 1}, i_{q 2}$, and $i_{d 2}$ are the $q$ - and $d$-axis components of the primary and secondary winding currents, while $V_{q 1}, V_{d 1}, V_{q 2}, V_{d 2}$ and $\lambda_{q 1}, \lambda_{d 1}, \lambda_{q 2}, \lambda_{\mathrm{d} 2}$, are the $q$ - and $d$-axis components of the primary and secondary winding voltages and fluxes. $L_{s 1}$ and $L_{s 2}$ are the self-inductances and $L_{m}$ is the magnetization inductance. The angular frequency of the grid voltage is indicated as $\omega_{e}$. The secondary windings are connected to the TTR and TLI, and thus, the phase winding voltages are given by:

$$
\bar{V}_{q 2}=\bar{V}_{q T T R}-\bar{V}_{q T L I}, \quad \bar{V}_{d 2}=\bar{V}_{d T T R}-\bar{V}_{d T L I}
$$




\subsection{Vienna Rectifier Model}

The Vienna rectifier switches at the fundamental frequency, according to Table 1 , where $\theta_{e}$ is the angular displacement of the fundamental harmonic of the winding phase voltage and $\alpha$ is the switching angle of $S_{i j},(i=a, b, c$ and $j=1,2)$.

Table 1. Vienna rectifier switching table.

\begin{tabular}{ccc}
\hline & $0<\theta_{e}<\alpha$ & if $i_{a g}>0=>S_{a 1}$ ON $S_{a 2}$ OFF \\
Phase $a$ & if $i_{a g}<0=>S_{a 1}$ OFF $S_{a 2}$ ON \\
& $2 \pi-\alpha<\theta_{e}<2 \pi$ & if $i_{b g}>0=>S_{b 1}$ ON $S_{b 2}$ OFF \\
Phase $b$ & $5 / 3 \pi<\theta_{e}<\alpha+2 / 3 \pi$ & if $i_{b g}<0=>S_{b 1}$ OFF $S_{b 2}$ ON \\
& $2 / 3 \pi-\alpha<\theta_{e}<2 / 3 \pi$ & \\
\hline Phase $c$ & $4 / 3 \pi<\theta_{e}<\alpha+4 / 3 \pi$ & if $i_{c g}>0=>S_{c 1}$ ON $S_{c 2}$ OFF \\
& $1 / 3 \pi-\alpha<\theta_{e}<1 / 3 \pi+\alpha$ & if $i_{c g}<0=>S_{c 1}$ OFF $S_{c 2}$ ON \\
\hline
\end{tabular}

Assuming the output voltage $V_{D C}$ is constant, actual values of Vienna rectifier input phase voltages $V_{\text {iTTR }}$ are thus given by:

$$
V_{i T T R}=S_{i j} \frac{l_{i j}-1}{2} V_{D C^{\prime}}, \quad \begin{aligned}
& -\alpha<\varphi_{T T R}<\alpha \\
& l_{i j}=0,1,2 .
\end{aligned}
$$

To avoid improper operations leading to extra power losses and voltage distortion, the angular displacement $\varphi_{T T R}$ between the fundamental harmonics of voltage $V_{\text {iTTR }}$ and current must be set lower than $|\alpha|$. Dealing with an electrical power generation application, a vector diagram of AC variables is shown in Figure $4 \mathrm{a}$, where $\varphi$ is the phase displacement between the PMSG back-EMF $\bar{E}_{g}$ and the current $\bar{I}$. $\delta$ represents the angle between the voltage $\bar{V}_{T T R}$ and the $q$ axis, and is set to allow a reactive power flow between the Vienna rectifier and PMSG, associated to the inductive elements of the electrical machine.

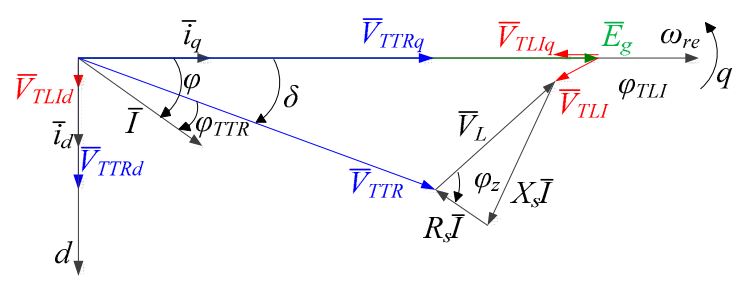

(a)

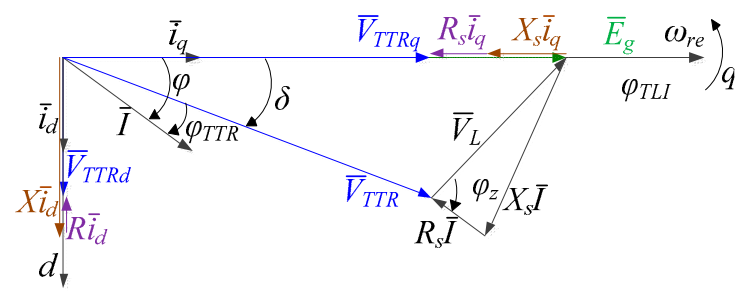

(b)

Figure 4. Vector diagram of AC variables: (a) considering $V_{T L I}$, (b) neglecting $V_{T L I}$.

Neglecting, for simplicity, the voltage $V_{T L I}$ generated by the auxiliary inverter, which is an independent variable and whose amplitude is significantly lower than $V_{i 1 T T R}$, the amplitude of the fundamental harmonic of the TTR input voltage $V_{\text {iTTTR }}$ is obtained as a function of the switching angle $\alpha$ and DC bus voltage $V_{D C}$ as follows:

$$
\left|\bar{V}_{i 1 T T R}\right|=\frac{2}{\pi} V_{D C^{\prime}} \cos (\alpha), m_{T T R}=\frac{\left|V_{i 1 T T R}\right|}{V_{D C}{ }^{\prime}}
$$


where $m_{T T R}$ is the modulation index of the Vienna rectifier. According to the vector diagram of Figure $4 \mathrm{~b}, q d$ components of the voltage can be written as:

$$
\begin{gathered}
\left\{\begin{array}{c}
\bar{V}_{q T T R}=\left|\bar{V}_{i 1 T T R}\right| \cos (\delta) \\
\bar{V}_{d T T R}=\left|\bar{V}_{i 1 T T R}\right| \sin (\delta)
\end{array},\left\{\begin{array}{l}
\bar{i}_{q}=|\bar{I}| \cos (\varphi) \\
\bar{i}_{d}=|\bar{I}| \sin (\varphi)
\end{array},\left\{\begin{array}{l}
\bar{E}_{q g}=\left|\bar{E}_{g}\right| \\
\bar{E}_{d g}=0
\end{array},\right.\right.\right. \\
\left\{\begin{array}{l}
X \bar{i}_{q}=-|X \bar{I}| \sin (\varphi) \\
X \bar{i}_{d}=+\left|X_{s} \bar{I}\right| \cos (\varphi)^{\prime}
\end{array},\left\{\begin{array}{l}
R \bar{i}_{q}=-|R \bar{I}| \cos (\varphi) \\
R \bar{i}_{d}=-|R \bar{I}| \sin (\varphi)
\end{array}\right.\right.
\end{gathered}
$$

while the active and reactive powers are given by:

$$
\left\{\begin{array}{l}
P_{\text {TTR }}=\frac{3}{2}\left|\bar{V}_{i 1 T T R} \bar{I}\right| \cos (\delta-\varphi) \\
Q_{T T R}=\frac{3}{2}\left|\bar{V}_{i 1 T T R} \bar{I}\right| \sin (\varphi-\delta)^{\prime}
\end{array},\left\{\begin{array}{l}
P_{R}=-\frac{3}{2} R|\bar{I}|^{2} \\
Q_{X}=-\frac{3}{2} X|\bar{I}|^{2}
\end{array},\left\{\begin{array}{l}
P_{g}=\frac{3}{2}\left|\bar{E}_{q g} \bar{I}\right| \cos (\varphi) \\
Q_{g}=\frac{3}{2}\left|\bar{E}_{q g} \bar{I}\right| \sin (\varphi)
\end{array}\right.\right.\right.
$$

where $P_{T T R}$ and $Q_{T T R}$ are the active and reactive power, respectively, processed by the Vienna rectifier, $P_{R}$ and $Q_{X}$ are the active power wasted in the stator resistance $R$ and the reactive power due to the PMSG synchronous reactance $X_{s}$, respectively, while $P_{g}$ and $Q_{g}$ are the active and reactive power delivered by the PMSG, respectively.

Neglecting the rectifier power losses, the AC power generated by the PMSG is equal to the sum of the power dissipated in the DC bus capacitor resistances $R_{C 1}$ and $R_{C 2}$ and the power delivered to the load $R_{L}$. In the Laplace domain, $V_{D C}{ }^{\prime}$ and the capacitor voltages $V_{C 1}$ and $V_{C 2}$ are thus given by

$$
\left\{\begin{array}{l}
V_{D C}{ }^{\prime}(s)=\sqrt{R_{L}\left(P_{A C}(s)-\frac{V_{C 1}^{2}(s)}{R_{C 1}}-\frac{V_{C 2}^{2}(s)}{R_{C 2}}\right)} \\
V_{C 1}(s)=V_{D C}(s) \frac{s R_{C 1}\left(1+R_{C 2} C_{2}\right)}{R_{C 1}+R_{C 1}+s R_{C 1} R_{C 2}\left(C_{1}+C_{2}\right)} \\
V_{C 2}(s)=V_{D C^{\prime}}(s)-V_{C 1}(s) \\
P_{A C}(s)=\frac{3}{2}\left(V_{q T T R}(s) i_{q}(s)+V_{d T T R}(s) i_{d}(s)\right)
\end{array}\right.
$$

where $i_{n}$ is mainly given by the difference between the currents flowing through the two DC bus capacitors and it can be also computed as the sum of the currents flowing through the three branches of the Vienna rectifier:

$$
i_{n}=S_{a j} i_{a g}+S_{b j} i_{b g}+S_{c j} i_{c g}
$$

The averaged-value of $i_{n}$ during a switching period $T$ is given by

$$
\bar{i}_{n}=\frac{1}{T}\left(T_{O N a j} i_{a g}+T_{O N b j} i_{b g}+T_{O N c j} i_{c g}\right)=\left(d_{a j} i_{a g}+d_{b j} i_{b g}+d_{c j} i_{c g}\right)
$$

where $d_{i j}=T_{\text {ONij }} / T$ are the duty cycles of the bidirectional switches $S_{i j}$, according to Table 2. Figure 5 shows some simulations dealing with balanced and unbalanced DC bus voltages operations, while a block diagram of the Vienna rectifier mathematical model is shown in Figure 6.

Table 2. $d_{a j}, d_{b j}$ and $d_{c j}$.

\begin{tabular}{cccccc}
\hline Sector I & Sector II & Sector III & Sector VI & Sector V & Sector IV \\
$V_{a 1 T T R}>\mathbf{0}$ & $V_{a 1 T T R}>\mathbf{0}$ & $V_{a 1 T T R}<\mathbf{0}$ & $V_{a 1 T T R}<\mathbf{0}$ & $V_{a 1 T T R}<\mathbf{0}$ & $V_{a 1 T T R}>\mathbf{0}$ \\
$V_{b 1 T T R}<0$ & $V_{b 1 T T R}>\mathbf{0}$ & $V_{b 1 T T R}>\mathbf{0}$ & $V_{b 1 T T R}>\mathbf{0}$ & $V_{b 1 T T R}<\mathbf{0}$ & $V_{b 1 T T R}<\mathbf{0}$ \\
$V_{c 1 T T R}<\mathbf{0}$ & $V_{c 1 T T R}<\mathbf{0}$ & $V_{c 1 T T R}<\mathbf{0}$ & $V_{c 1 T T R}>\mathbf{0}$ & $V_{c 1 T T R}>\mathbf{0}$ & $V_{c 1 T T R}>\mathbf{0}$ \\
\hline$d_{a j}=\frac{V_{a 1 T T R}}{V_{D C}}$ & $d_{a j}=-\frac{V_{a 1 T T R}}{V_{D C} C^{\prime}}$ & $d_{a j}=-\frac{V_{a 1 T T R}}{V_{D C}}$ & $d_{a j}=-\frac{V_{a 1 T T R}}{V_{D C}}$ & $d_{a j}=\frac{V_{a 1 T T R}}{V_{D C}}$ & $d_{a j}=\frac{V_{a 1 T T R}}{V_{D C}}$ \\
\hline$d_{b j}=\frac{V_{b 1 T T R}}{V_{D C}}$ & $d_{b j}=\frac{V_{b 1 T T R}}{V_{D C}}$ & $d_{b j}=-\frac{V_{b 1 T T R}}{V_{D C}}$ & $d_{b j}=-\frac{V_{b 1 T T R}}{V_{D C}}$ & $d_{b j}=-\frac{V_{b 1 T T R}}{V_{D C}}$ & $d_{b j}=-\frac{V_{b 1 T T R}}{V_{D C}}$ \\
\hline$d_{c j}=-\frac{V_{c 1 T T R}}{V_{D C^{\prime}}}$ & $d_{c j}=-\frac{V_{c 1 T T R}}{V_{D C}}$ & $d_{c j}=\frac{V_{c 1 T T R}}{V_{D C^{\prime}}}$ & $d_{c j}=\frac{V_{c 1 T T R}}{V_{D C^{\prime}}}$ & $d_{c j}=\frac{V_{c 1 T T R}}{V_{D C^{\prime}}}$ & $d_{c j}=-\frac{V_{c 1 T T R}}{V_{D C}}$ \\
\hline
\end{tabular}




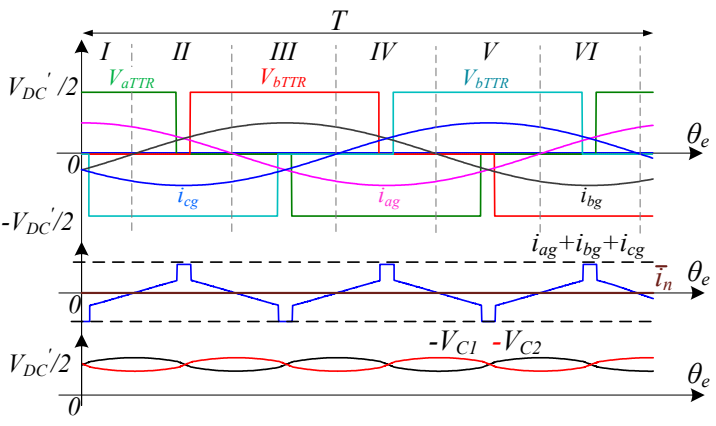

(a)

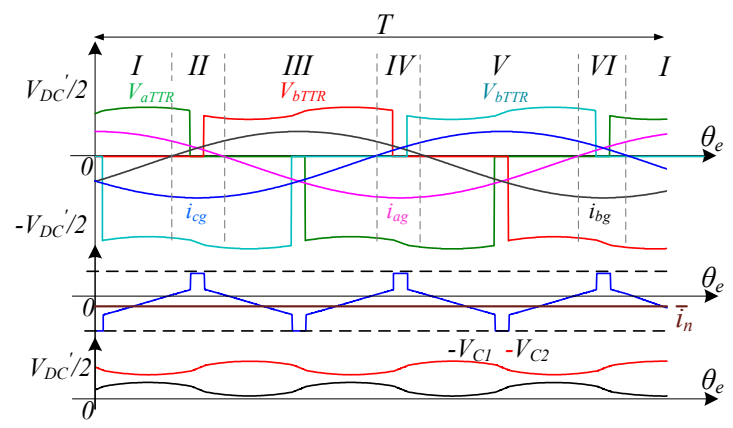

(b)

Figure 5. Averaged-value $i_{n}, i_{a b c g}, V_{c 1}, V_{c 2}$, and $V_{i T T R}$. (a) Balanced DC bus voltages, and (b) unbalanced DC bus voltages.

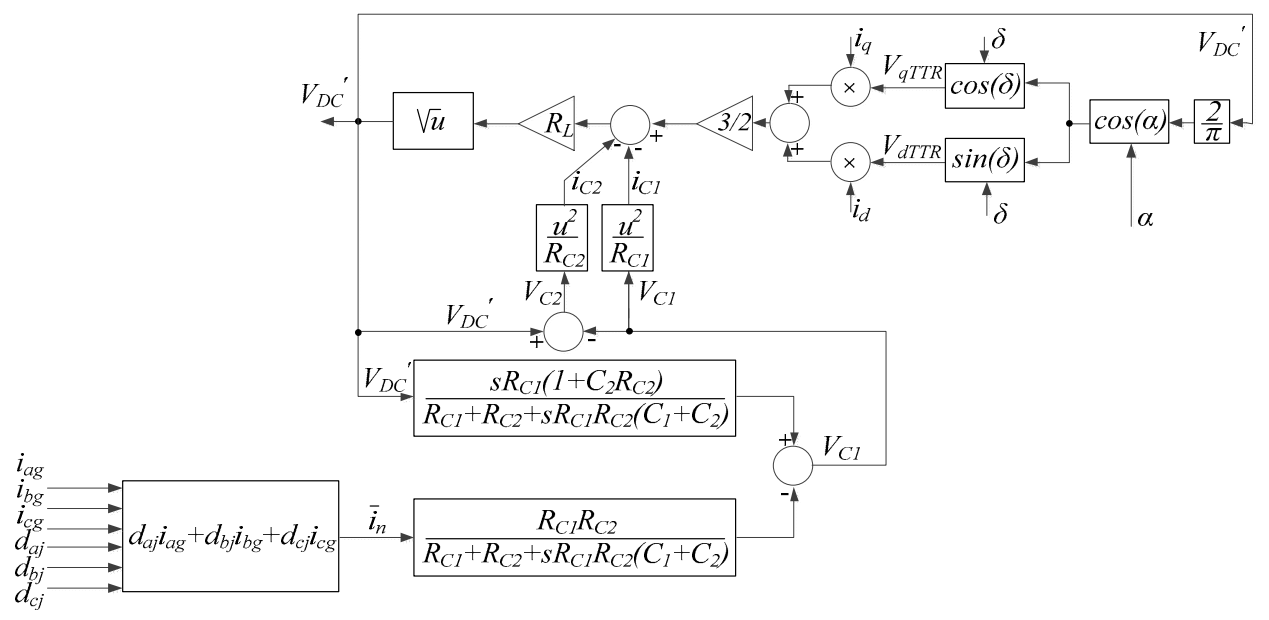

Figure 6. Block diagram of the Vienna rectifier model.

A non-null average $i_{n}$ leads to unbalanced DC bus voltages [16-18]; moreover, the mean value of fundamental voltages $V_{a 1 T T R}$ becomes negative if $V_{C 1}<V_{C 2}$ or positive if $V_{C 2}<V_{C 1}$. This is included in the TTR model by adding the term $\Delta V_{D C^{\prime}}=V_{C 1}-V_{C 2}$ :

$$
\left\{\begin{array}{l}
V_{a 1 T T R}=\left|V_{a 1 T T R}\right| \sin \left(\theta_{e}\right)+\Delta V_{D C^{\prime}} \\
V_{b 1 T T R}=\left|V_{b 1 T T R}\right| \sin \left(\theta_{e}-\frac{2}{3} \pi\right)+\Delta V_{D C^{\prime}} \\
V_{c 1 T T R}=\left|V_{c 1 T T R}\right| \sin \left(\theta_{e}+\frac{2}{3} \pi\right)+\Delta V_{D C^{\prime}}
\end{array}\right.
$$

According to Table 2, by replacing (21) into (20), $\bar{i}_{n}$ is given by

$$
\bar{i}_{n}=\left\{\begin{array}{lc}
m_{T T R} 0.5 I\left[-\cos \left(\varphi_{T T R}\right)-2 \cos \left(2 \theta_{e}-\frac{4 \pi}{3}-\varphi_{T T R}\right)\right]-2 I \frac{\Delta V_{D C^{\prime}}}{V_{D C^{\prime}}} \sin \left(\theta_{e}-\frac{2 \pi}{3}-\varphi_{T T R}\right), & 0<\theta_{e}<\frac{\pi}{3} \\
m_{T T R} 0.5 I\left[\cos \left(\varphi_{T T R}\right)+2 \cos \left(2 \theta_{e}-\varphi_{T T R}\right)\right]-2 I \frac{\Delta V_{D C^{\prime}}}{V_{D C^{\prime}}} \sin \left(\theta_{e}-\varphi_{T T R}\right), & \frac{\pi}{3}<\theta_{e}<\frac{2 \pi}{3} \\
m_{T T R} 0.5 I\left[-\cos \left(\varphi_{T T R}\right)-2 \cos \left(2 \theta_{e}-\frac{2 \pi}{3}-\varphi_{T T R}\right)\right]-2 I \frac{\Delta V_{D C^{\prime}}}{V_{D C^{\prime}}} \sin \left(\theta_{e}+\frac{2 \pi}{3}-\varphi_{T T R}\right), & \frac{2 \pi}{3}<\theta_{e}<\pi \\
m_{T T R} 0.5 I\left[\cos \left(\varphi_{T T R}\right)+2 \cos \left(2 \theta_{e}-\frac{4 \pi}{3}-\varphi_{T T R}\right)\right]+2 I \frac{\Delta V_{D C^{\prime}}}{V_{D C^{\prime}}} \sin \left(\theta_{e}-\frac{2 \pi}{3}-\varphi_{T T R}\right), & \pi<\theta_{e}<\frac{4 \pi}{3} \\
m_{T T R} 0.5 I\left[-\cos \left(\varphi_{T T R}\right)-2 \cos \left(2 \theta_{e}-\varphi_{T T R}\right)\right]-2 I \frac{\Delta V_{D C^{\prime}}}{V_{D C^{\prime}}} \sin \left(\theta_{e}-\varphi_{T T R}\right), & \frac{4 \pi}{3}<\theta_{e}<\frac{5 \pi}{3} \\
m_{T T R} 0.5 I\left[\cos \left(\varphi_{T T R}\right)+2 \cos \left(2 \theta_{e}-\frac{2 \pi}{3}-\varphi_{T T R}\right)\right]+2 I \frac{\Delta V_{D C^{\prime}}}{V_{D C^{\prime}}} \sin \left(\theta_{e}+\frac{2 \pi}{3}-\varphi_{T T R}\right), & \frac{5 \pi}{3}<\theta_{e}<\pi
\end{array}\right.
$$

\subsection{TLI Model}

A key task of the TLI present in the AHUTR topology is to compensate all low-order voltage harmonics generated by the step-modulated Vienna rectifier [12]. For this reason, the TLI reference 
phase voltage is equal to the difference between the AC side input voltage $V_{i T T R}$ and its fundamental component $V_{\text {i1TTR, }}$ as shown in Figure 7.

$$
V_{i T L I}^{*}=V_{i T T R}-V_{i 1 T T R}
$$

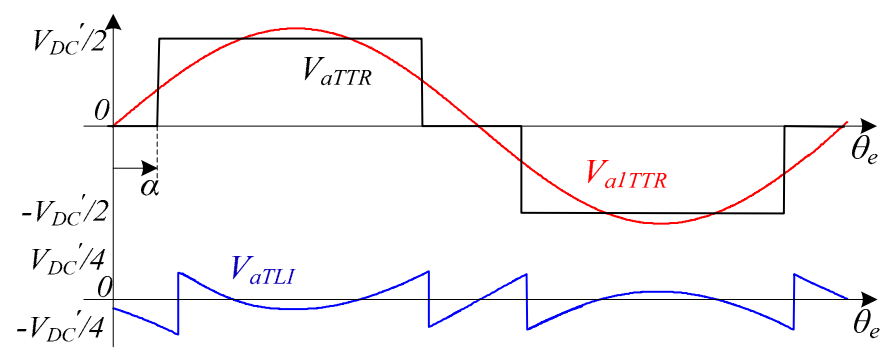

Figure 7. Two-level inverter (TLI) reference voltage for active power filtering.

Phase voltages $V_{\text {iTTR }}$ encompass some zero sequence components, such as the $3^{\text {rd }}, 9^{\text {th }}, 27^{\text {th }}$, and $81^{\text {st }}$, that will not result in corresponding currents in the PMSG because the considered open-end winding topology is composed by two isolated converters. Hence, these harmonics can be neglected in the TLI reference voltages $V_{\text {iTLI }}{ }^{*}$. This leads to a reduction of TLI DC bus voltage and, accordingly, to a positive impact on TLI losses. TLI reference voltages $V_{a b c T L I}{ }^{*}$ are thus given by

$$
\left\{\begin{aligned}
V_{a T L I}^{*}\left(n, \theta_{e}\right) & =\sum_{n=5,7,11,13} b_{a n} \times \sin \left(n \theta_{e}-\varphi_{n}\right) \\
V_{b T L I}{ }^{*}\left(n, \theta_{e}\right) & =\sum_{n=5,7,11,13} b_{b n} \times \sin \left(n \theta_{e}-\varphi_{n}-\frac{2 \pi}{3}\right) \\
V_{c T L I}{ }^{*}\left(n, \theta_{e}\right) & =\sum_{n=5,7,11,13} b_{c n} \times \sin \left(n \theta_{e}-\varphi_{n}+\frac{2 \pi}{3}\right)
\end{aligned}\right.
$$

Figure 8 shows the $V_{a T L I}{ }^{*}$ waveform when considering a different set of zero sequence components. For each case, the minimum $V_{D C}{ }^{\prime \prime} / V_{D C}$ ' requirement has been computed as shown in Figure 9, while current and voltage THDs are provided in Figure 10. At medium-high values of the modulation index $m_{T T R}$, a proper suppression of the effects of the low-order voltage harmonics produced by the Vienna rectifier is simply achieved by compensating the $5^{\text {th }}$ and $7^{\text {th }}$ harmonics. However, at low $m_{T T R}$, additional harmonics must be considered to keep the THDs suitably low.

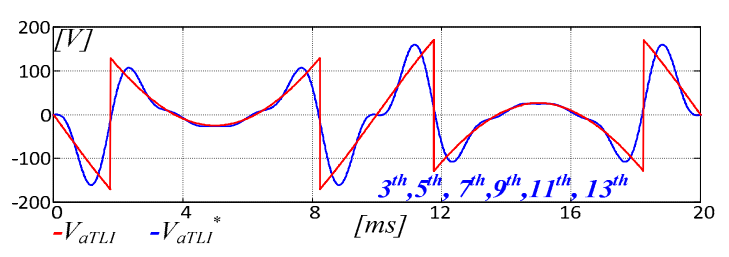

(a)

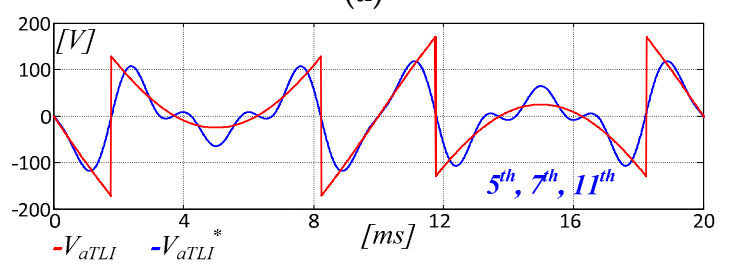

(c)

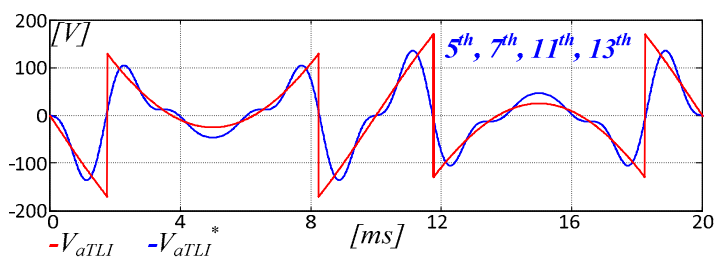

(b)

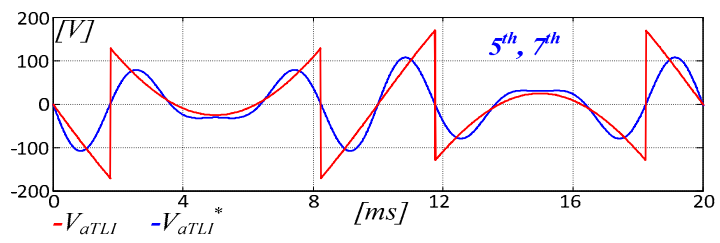

(d)

Figure 8. TLI reference voltage approximation. (a) $3^{\text {rd }}, 5^{\text {th }}, 7^{\text {th }}, 9^{\text {th }}, 11^{\text {th }}, 13^{\text {th }}$. (b) $5^{\text {th }}, 7^{\text {th }}, 11^{\text {th }}, 13^{\text {th }}$. (c) $5^{\text {th }}, 7^{\text {th }}, 11^{\text {th }}$. (d) $5^{\text {th }}, 7^{\text {th }}$. 


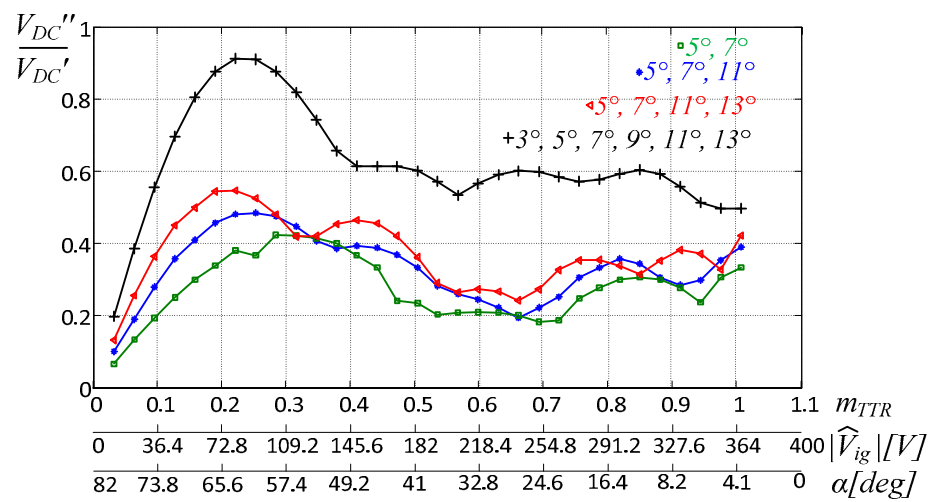

Figure 9. Minimum $V_{D C}{ }^{\prime \prime} / V_{D C}{ }^{\prime}$ requirement vs. peak amplitude of PMSG phase voltage, $m_{T T R}$, and $\alpha$.
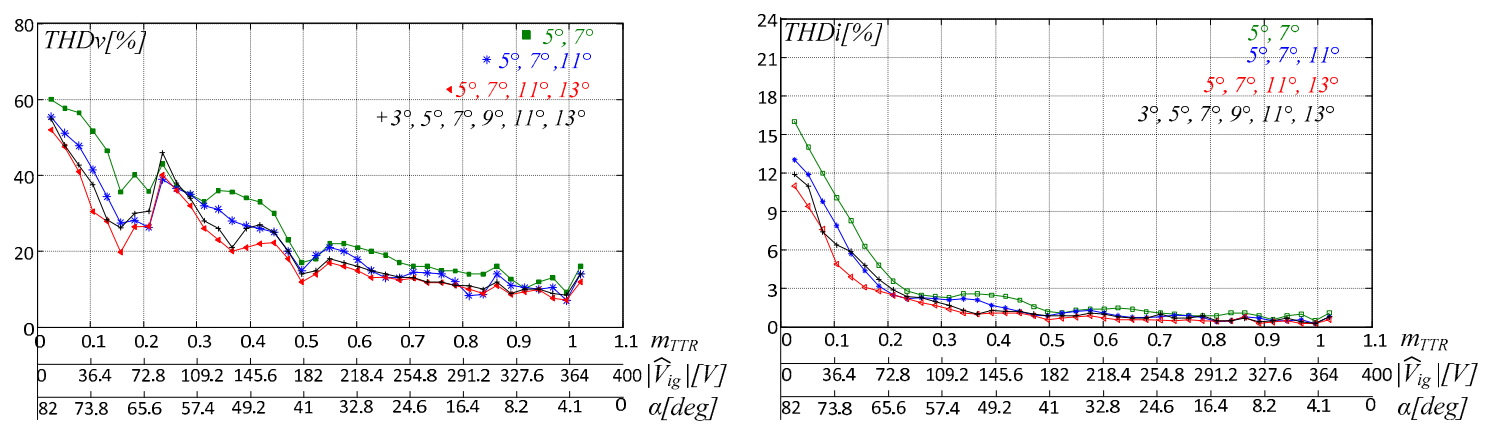

Figure 10. THDv and THDi vs. the peak amplitude of PMSG phase voltage.

As shown in Figure 2, a closed loop input current control system is added to the predictive filter in order to cope with unmodeled non-linearities and improve the input current waveform as well as the system dynamic response. By equaling the active power generated by the PMSG to the output DC power, the reference $q$-axis current $i_{q}{ }^{*}$ is computed from actual values of $\alpha, \delta$ and the output DC current $i_{D C}$ as:

$$
i_{q}^{*}=\frac{\pi i_{D C}}{3 \cos (\alpha) \cos (\delta)}, i_{d}^{*}=0
$$

The $d$-axis reference current $i_{d}{ }^{*}$ can be simply set to zero or suitably determined in case of interior permanent magnet structures in order to operate the PMSG according to a maximum power per ampere strategy.

Another key function of the TLI is to balance the voltage across the DC bus capacitors of the Vienna rectifier, making unnecessary additional circuits. As shown in Figure 2, this goal is obtained by acting on the $q$-axis component of the TLI reference current in order to control the amplitude of $i_{n}$, which is given by the difference between the currents flowing through the two DC bus capacitors.

The DC side of the TLI is modeled by balancing the AC and DC side power, neglecting the power switches losses (Equation (26)). The TLI DC-link includes the resistance $R_{C T}$ representing the floating capacitor losses, while $V_{q T L I}$ and $V_{d T L I}$ are the voltage components of TLI $V_{j T L I}$ in the $q d$ axis, as shown in Figure 11.

$$
\left\{\begin{array}{l}
P_{A C}=P_{D C 2}=\frac{3}{2}\left(V_{q T L I} i_{q}+V_{d T L I} i_{d}\right) \\
P_{D C 2}=V_{D C} i_{D C}^{\prime \prime}+\frac{V_{D C} C^{\prime \prime 2}}{R_{C T}}=V_{D C} C_{T} s V_{D C}{ }^{\prime \prime}+\frac{V_{D C} C^{\prime \prime 2}}{R_{C T}}=\frac{3}{2}\left(V_{q T L I} i_{q}+V_{d T L I} i_{d}\right)
\end{array}\right.
$$




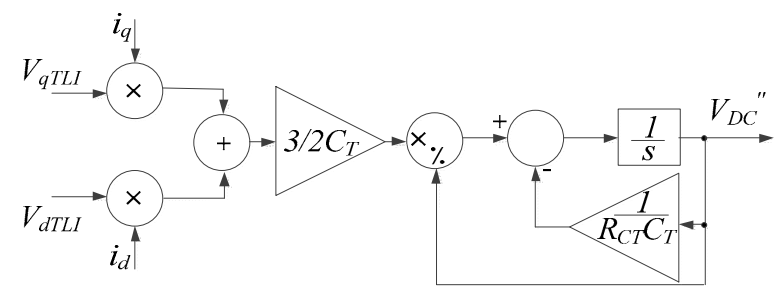

Figure 11. Block diagram of TLI model.

\section{Model Validation}

An electric power generation application has been considered for validating the value-averaged model. Specifically, the proposed model represented with the blocks scheme of Figure 12 has been implemented in a Simulink environment and compared to a detailed model of the system developed in the same environment exploiting the SimPower System Toolbox, which is a circuit-based modeling platform widely used for the simulation of power electronic converters, electromechanical systems, and their control systems. The last model includes both converter topologies. The control scheme used on both models is shown in Figure 2, including low-order harmonic compensation and DC bus capacitor voltages balancing [14]. Simulation settings are summarized in Table 3, where $k_{P \alpha}$ and $k_{I \alpha}$ are the proportional and integral gains of the output DC voltage controller, while $k_{P i q}, k_{I i q}, k_{P i d}$, and $k_{\text {Iid }}$ are the proportional and integral gains of $q d$ PMSG current regulators; $k_{P i n}$ and $k_{\text {Iin }}$ are the proportional and integral gains of the Vienna rectifier DC bus voltage equalization system; and $k_{P T L I}$ and $k_{I T L I}$ are the proportional and integral gains of the TLI DC Bus voltage controller. Figures 13 and 14 show simulation results obtained with the SimPower System model and the averaged-value model, showing a purposely generated Vienna rectifier DC bus voltage unbalance with the balance system not activated. Specifically, capacitor voltages $V_{C 1}$ and $V_{C 2}$, which at the beginning are equal because $R_{C 1}$ and $R_{C 2}$ are both set to $1000 \Omega$, diverge after $t=3 \mathrm{~s}$ because $R_{C 2}$ is changed to $600 \Omega$ in order to generate the voltage unbalance. The $i_{n}$ current is zero when capacitor voltages are balanced and greater than zero after $t=3 \mathrm{~s}$, while DC bus voltages $V_{D C}{ }^{\prime}$ and $V_{D C} C^{\prime \prime}$ do not vary. A zoomed-in view of the balanced and unbalanced steady-state operations of Figures 13 and 14 are shown in Figures 15 and 16, confirming a good matching between the results obtained with the two models. Figures $15 \mathrm{~d}$ and $16 \mathrm{~d}$ show the instantaneous Vienna rectifier power losses $P_{T T R}$, TLI power losses $P_{T L I}$, and PMSG power losses $P_{L g}$ during balanced DC bus capacitors. A one-time variation of the references of the output voltage and the TLI DC bus voltage is considered in Figures 17 and 18, while a load variation is shown in Figures 19 and 20. The results achieved with the two models are very close, but using the averaged-value model, the simulation time is roughly one third. In particular, all simulations have been accomplished on an Intel ${ }^{\circledR}$ CoreTM i7 CPU with $2.60 \mathrm{GHz}$ and 16 GB RAM running a 64-bit Windows 10 operating system. Simulation results shown in Figures 13-20 required three minutes computing time using the SimPower System model with a $10^{-6} \mathrm{~s}$ time step. A $10^{-5} \mathrm{~s}$ time step can be used with the averaged-value model, because high frequency voltage and current harmonics are neglected, leading to only ten seconds to accomplish the same simulation.

Table 3. System parameters.

\begin{tabular}{cc|cc|c|c}
\hline \multicolumn{1}{c|}{ PMSG } & \multicolumn{2}{c|}{ Vienna } & TLI & Control Gains \\
\hline Power Rating & $3 \mathrm{~kW}$ & IGBT Ratings & $600 \mathrm{~V}, 20 \mathrm{~A}$ & $200 \mathrm{~V}, 10 \mathrm{~A}$ & $K_{P \alpha}=0.1, K_{I \alpha}=10$ \\
Rated Voltage & $575 V_{D C}$ & DC-Link Voltage & $200 \mathrm{~V}$ & $100 \mathrm{~V}$ & $K_{P i q g}=80, K_{\text {Iiqg }}=1000$ \\
Rated Current & $6.5 \mathrm{~A}$ & DC Bus Capacitors & $470 \mu \mathrm{F}\left(C_{1}, C_{2}\right)$ & $470 \mu \mathrm{F}\left(C_{T}\right)$ & $K_{P i d g}=80, K_{I i d g}=1000$ \\
Phase Inductance & $20 \mathrm{mH}$ & Load & $50 \Omega$ & $/ /$ & $K_{\text {Pin }}=0.2, K_{\text {Iin }}=2$ \\
Stator Resistance & $4.3 \Omega$ & Capacitors Resistance & $1000 \Omega\left(R_{C 1}, R_{C 2}\right)$ & $600 \Omega\left(R_{C T}\right)$ & $K_{P T L I}=2, K_{I T L I}=30$ \\
PM Flux & $0.57 \mathrm{~Wb}$ & Switching Frequency & $50 \mathrm{~Hz}$ & $40 \mathrm{kHz}$ & \\
\hline
\end{tabular}




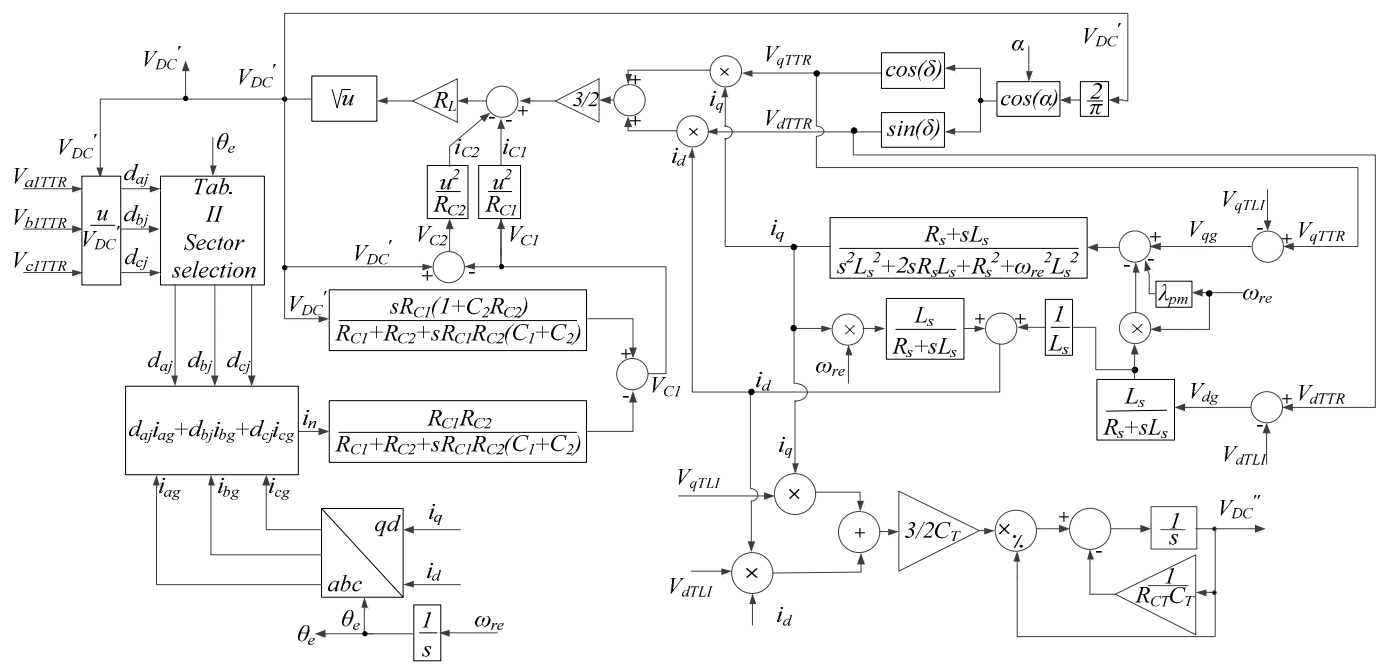

Figure 12. Block diagram of the developed averaged-value model.

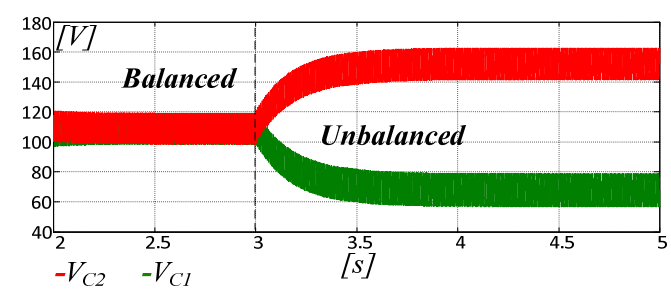

(a)

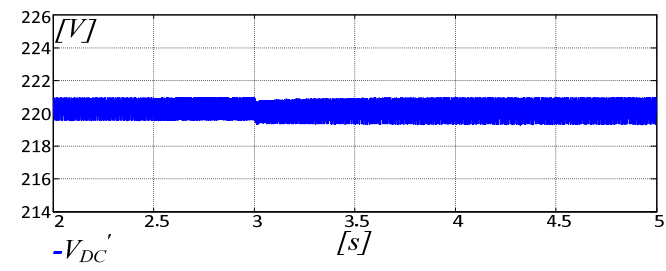

(c)

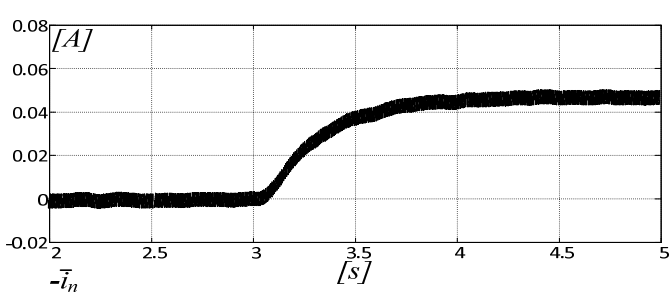

(b)

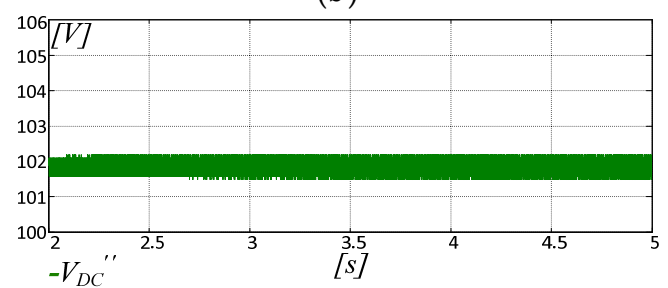

(d)

Figure 13. SimPower System model. (a) DC bus capacitor voltages $V_{C 1}$ and $V_{C 2}$. (b) $i_{n}=i_{C 1}-i_{C 2}$. (c) output voltage $V_{D C^{\prime}}$. (d) TLI DC bus voltage $V_{D C^{\prime \prime}}$.

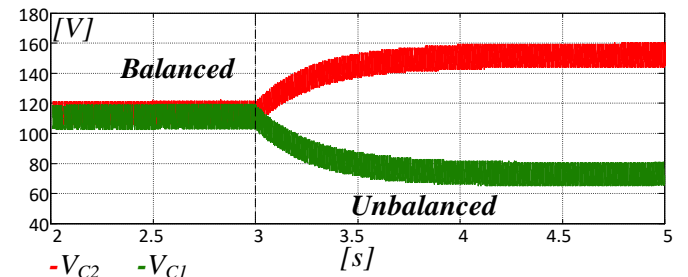

(a)

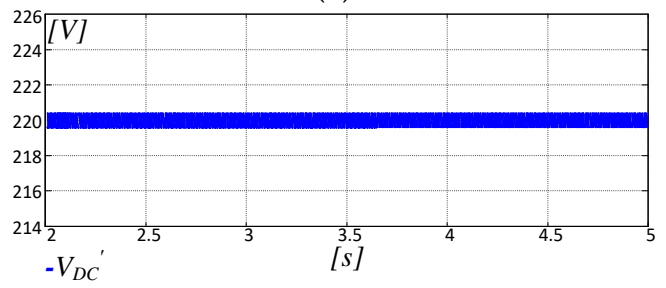

(c)

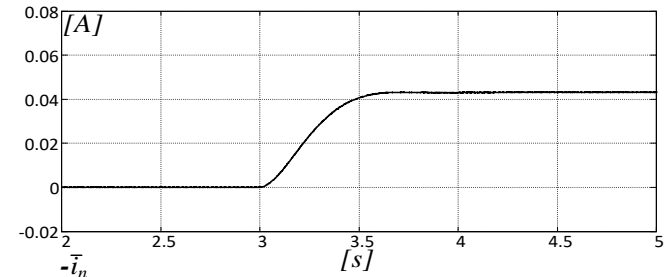

(b)

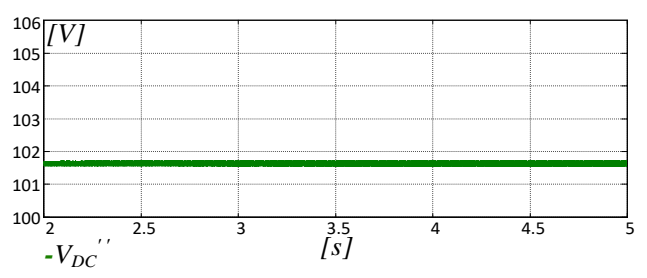

(d)

Figure 14. Averaged-value model. (a) DC bus capacitor voltages $V_{C 1}$ and $V_{C 2}$. (b) $i_{n}=i_{C 1}-i_{C 2}$. (c) output voltage $V_{D C^{\prime}}$. (d) TLI DC bus voltage $V_{D C}{ }^{\prime \prime}$. 


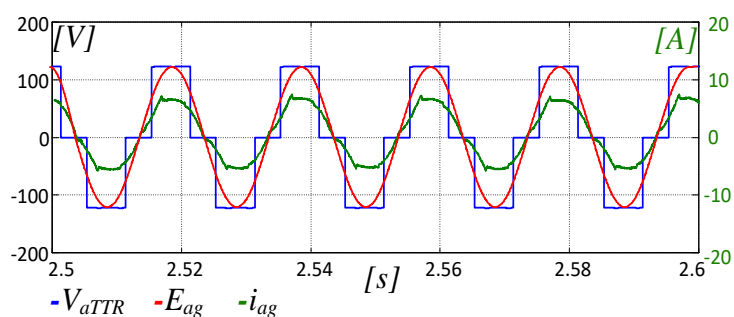

(a)

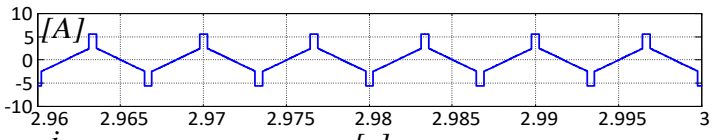

$$
-i_{n}
$$

$\sqrt[10]{[A]}$

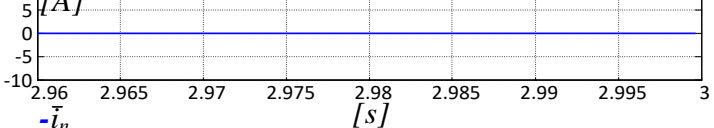

150

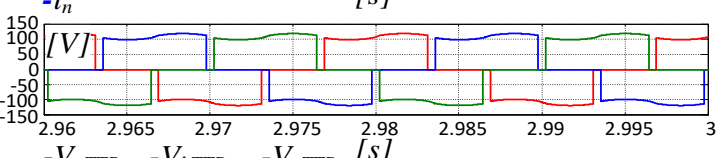

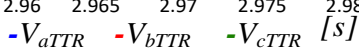

(c)

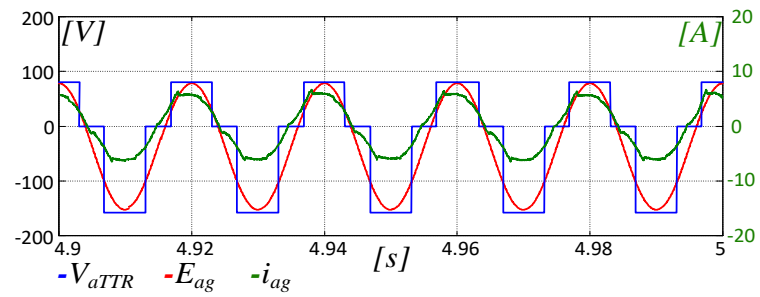

(b)

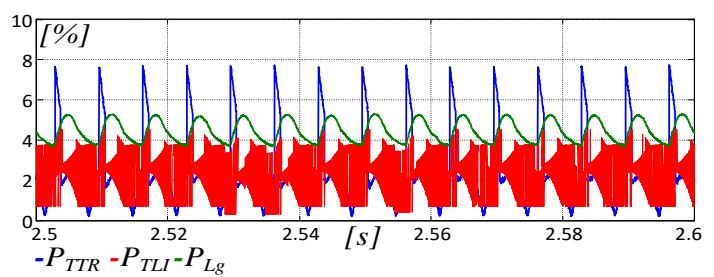

(d)

Figure 15. SimPower System model. (a) Balanced DC bus capacitor voltage operations, $V_{a T T R}, E_{a g}$, and $i_{\text {ag. }}$. (b) Unbalanced DC bus capacitor voltage operations. (c) Current $i_{n}$, average value $\bar{i}_{n}$, and AC input Vienna voltages $V_{i T T R}$. (d) TRR power losses $P_{\text {TTR }}$, TLI power losses $P_{\text {TLI }}$, and PMSG power losses $P_{L g}$.

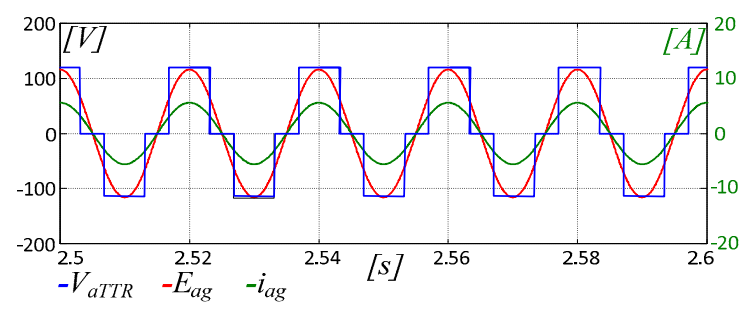

(a)
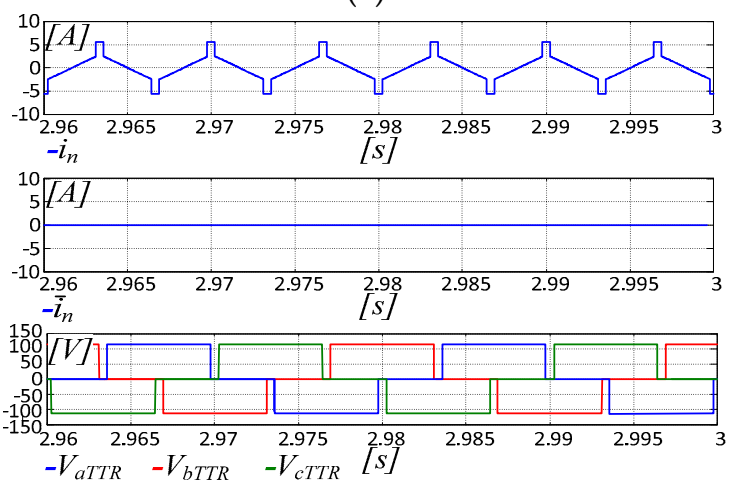

(c)

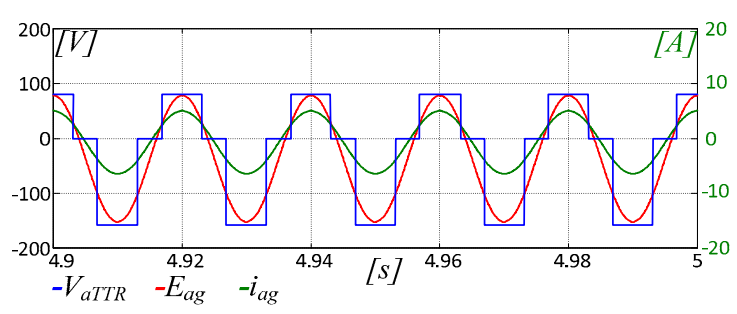

(b)

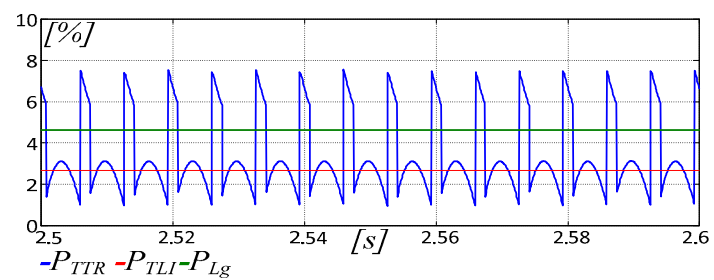

(d)

Figure 16. Averaged-value model. (a) Balanced DC bus capacitor voltage operations, $V_{a T T R}, E_{a g}$, and $i_{\text {ag. }}$. (b) Unbalanced DC bus capacitor voltage operations. (c) Current $i_{n}$, average value $\bar{i}_{n}$, and AC input Vienna voltages $V_{\text {iTTR. }}$ (d) TRR power losses $P_{\text {TTR }}$, TLI power losses $P_{T L I}$, and PMSG power losses $P_{L g}$. 


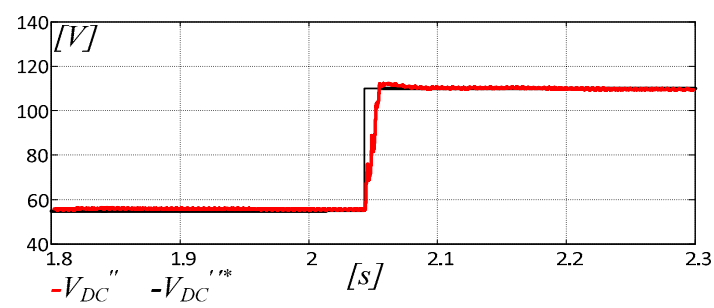

(a)

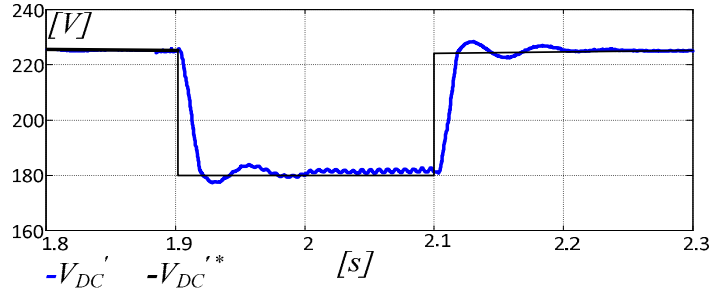

(b)

Figure 17. SimPower System model. One-time variation of $V_{D C}{ }^{\prime}$ and $V_{D C}$ " references. (a) TLI DC bus voltage $V_{D C} C^{\prime \prime}$. (b) Output voltage $V_{D C^{\prime}}$.

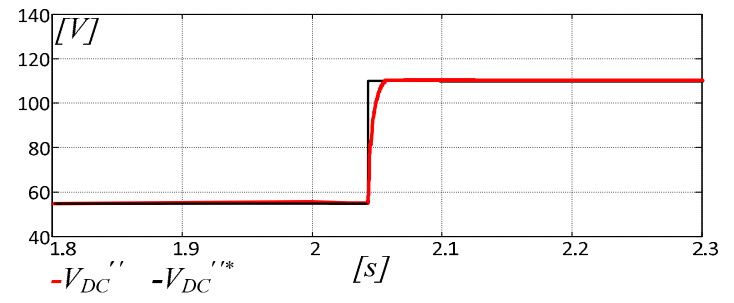

(a)

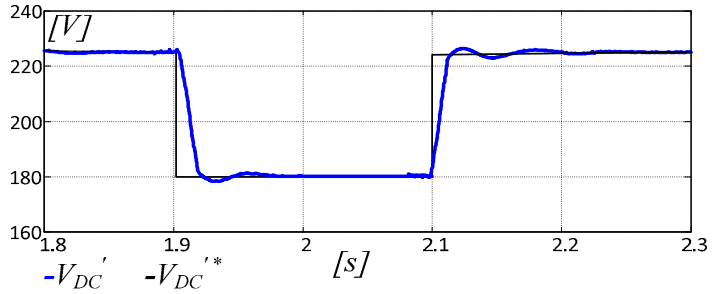

(b)

Figure 18. Averaged-value model. One-time variation of $V_{D C}{ }^{\prime}$ and $V_{D C}$ " references. (a) TLI DC bus voltage $V_{D C^{\prime \prime}}$. (b) Output voltage $V_{D C^{\prime}}$.

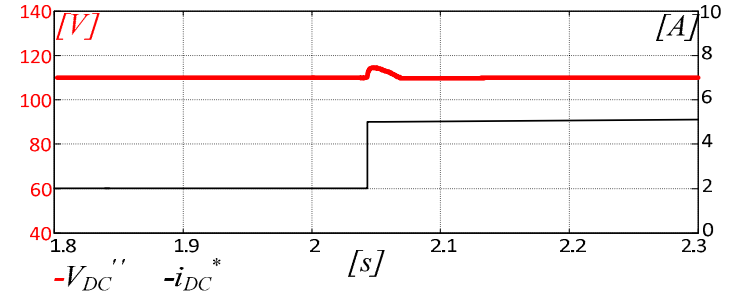

(a)

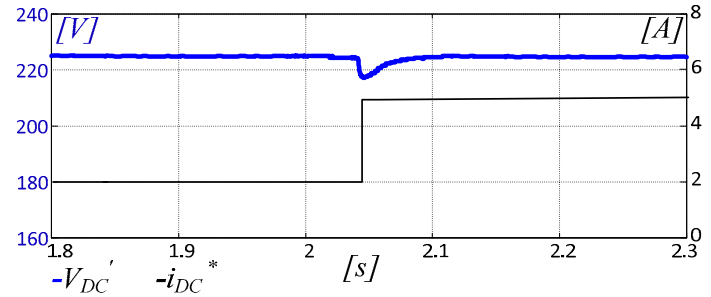

(b)

Figure 19. SimPower System model. Load variation $i_{D C}{ }^{*}$. (a) TLI DC bus voltage $V_{D C}{ }^{\prime \prime}$. (b) Output voltage $V_{D C^{\prime}}$.

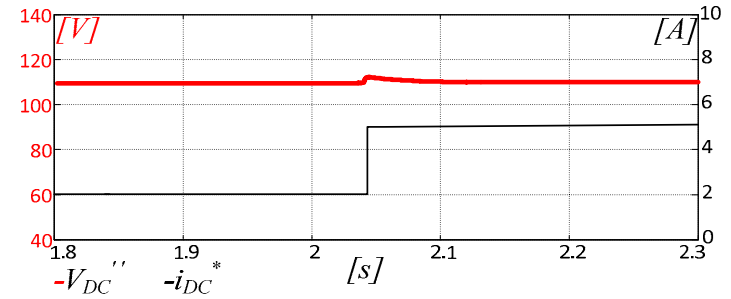

(a)

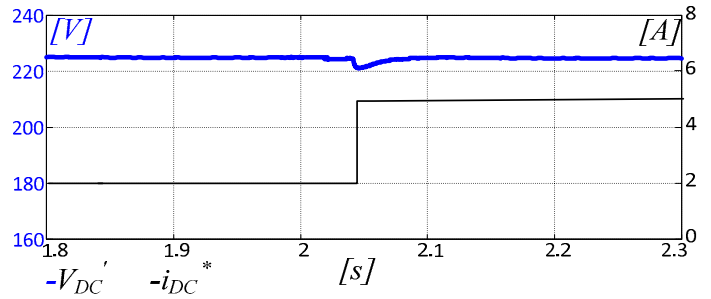

(b)

Figure 20. Averaged-value model. Load variation $i_{D C}{ }^{*}$. (a) TLI DC bus voltage $V_{D C}{ }^{\prime}$. (b) Output voltage $V_{D C^{\prime}}$.

Figure 21 displays the maximum errors between the quantities carried out by the two models, confirming a good accuracy of the proposed average model in a wide range of load conditions. 


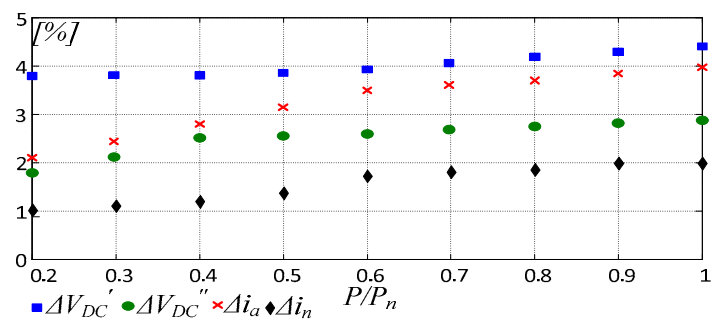

(a)

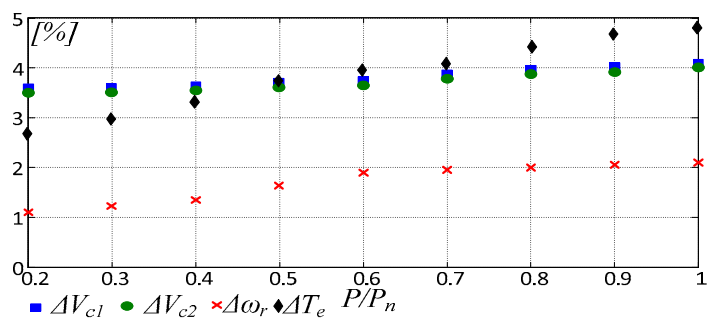

(b)

Figure 21. Percentage error between SymPower System and averaged model vs. the power expressed in per unit $P / P_{n}$. (a) Errors of $V_{D C^{\prime}}, V_{D C}{ }^{\prime \prime}, i_{a}$, and $i_{n}$. (b) Errors of $V_{c 1}, V_{c 2}, \omega_{r}$ and $T_{e}$. Note: $\omega_{r}=200$ $\mathrm{rad} / \mathrm{s}, V_{D C^{\prime}}=400 \mathrm{~V}$, and $V_{D C^{\prime \prime}}=100 \mathrm{~V}$.

\section{Experimental Assessment}

The accuracy of the AHUTR analytical model has also been verified comparing the results from the model with those from an experimental test rig consisting of $1 \mathrm{~kW}$ AHUTR supplying an open-end-winding PMSG, mechanically coupled to a $2.6 \mathrm{~kW}$ PM synchronous motor drive used as a prime mover. Technical specifications of the PMSG are given in Table 4. This AHUTR supplied DC loads at $400 \mathrm{~V}$ through the Vienna rectifier equipped with insulated gate bipolar transistors (IGBTs) whose technical data are listed in Table 5. The TLI was realized with low-voltage power metal-oxide-semiconductor field-effect transistor (MOSFETs) and operated at $40 \mathrm{kHz}, V_{D C}{ }^{\prime \prime}=100 \mathrm{~V}$. Technical data of the power MOSFETs are reported in Table 6. The TLI floating capacitor and both capacitors $C_{1}, C_{2}$ were equal to $470 \mu \mathrm{F}$. The DC load was modified using a variable power resistor. A single dSPACE DS1103 control board was used to control the Vienna rectifier and the TLI, while a 2048 ppr encoder was used to measure the rotor position $\theta_{r}$ of the PMSG. The experimental setup is shown in Figure 22. The currents and voltages were measured by using a dedicated sensing board equipped with the current transducer LEM LA 55-P and voltage transducer LEM LV 25-P.

Table 4. PMSG technical data.

\begin{tabular}{cccccccc}
\hline $\boldsymbol{P}_{\boldsymbol{n}}(\mathbf{k W})$ & $\boldsymbol{L}_{\boldsymbol{s}}(\mathbf{m H})$ & $V_{\boldsymbol{s}}(\mathrm{V})$ & $\boldsymbol{R}_{\boldsymbol{s}}(\boldsymbol{\Omega})$ & $\boldsymbol{I}_{\boldsymbol{s}}(\mathrm{A})$ & $\lambda_{\boldsymbol{P M}}(\mathbf{W b})$ & $\omega_{\boldsymbol{r}}(\mathbf{k r p m})$ & Pole Pairs \\
\hline 1 & 20 & 565 & 4.8 & 6.5 & 1.53 & 2 & 3 \\
\hline
\end{tabular}

Table 5. Technical specifications of STGW30NC60KD IGBT.

\begin{tabular}{ccccc}
\hline$V_{c e}(\mathrm{~V})$ & $V_{c e}($ on $)(\mathrm{V})$ & $i_{R M S}(\mathrm{~A})$ & $t_{\text {rise }}(\mathrm{ns})$ & $t_{\text {fall }}$ (ns) \\
\hline 600 & 2.1 & 30 & 27 & 160 \\
\hline
\end{tabular}

Table 6. Technical specifications of IRFB5615PBF MOSFET.

\begin{tabular}{ccccc}
\hline$V_{D S}(\mathrm{~V})$ & $R_{D S}(\mathrm{~m})$ & $\boldsymbol{I}_{\boldsymbol{D}}(\mathrm{A})$ & $\boldsymbol{t}_{\text {rise }}(\mathrm{ns})$ & $\boldsymbol{t}_{\text {fall }}(\mathrm{ns})$ \\
\hline 150 & 32 & 35 & 8.9 & 17.2 \\
\hline
\end{tabular}




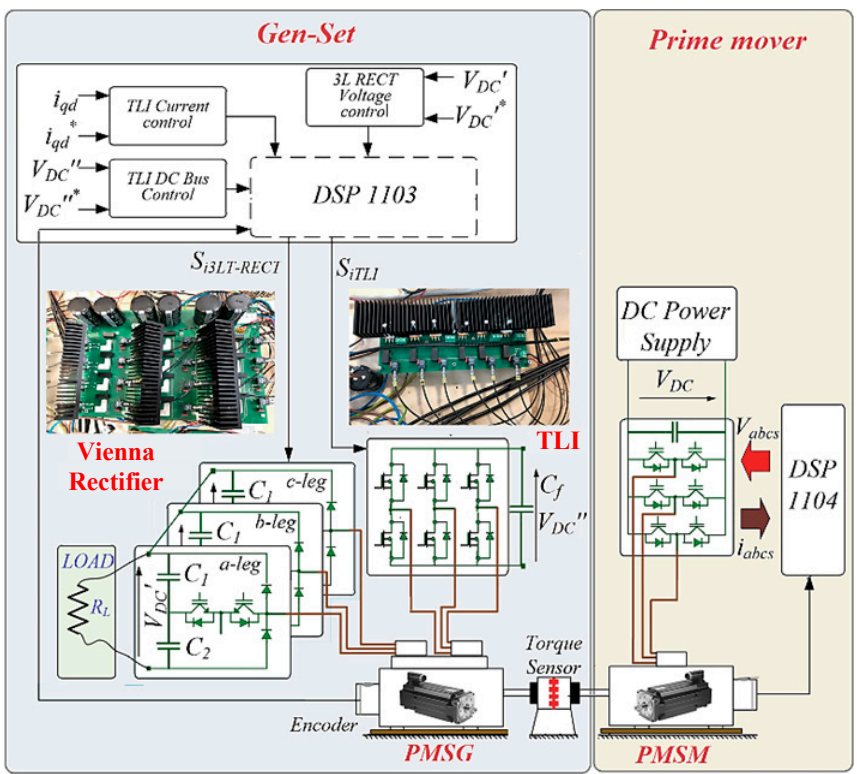

(a)
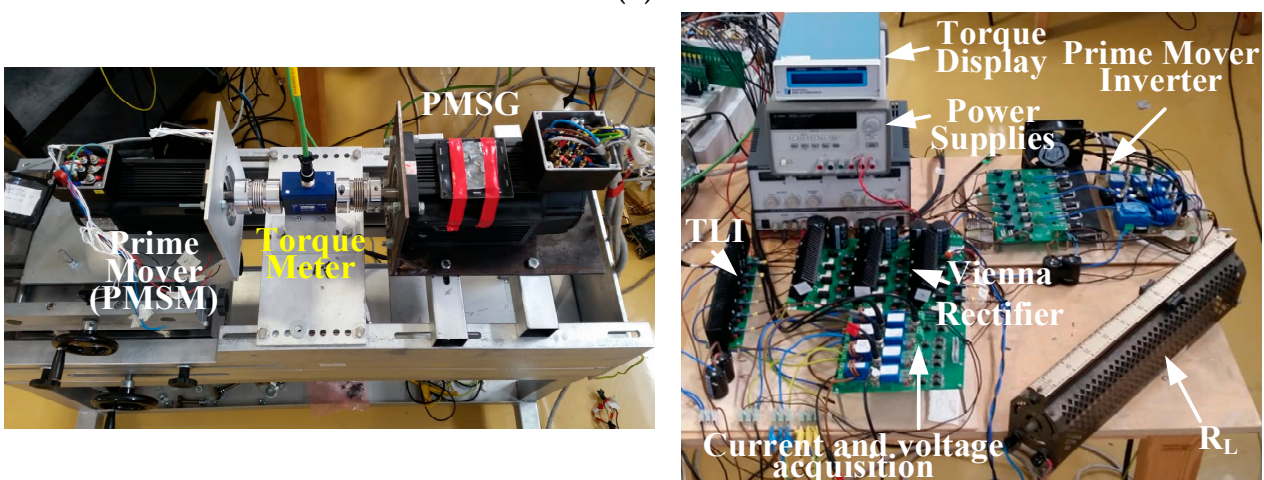

(b)

Figure 22. Experimental test bench. (a) Block scheme. (b) Experimental setup.

The experimental results shown in Figure 23 were obtained by imposing a transient voltage to $V_{D C^{\prime}}$ from $400 \mathrm{~V}$ to $320 \mathrm{~V}$ by keeping a constant resistor value $R_{L}=80 \Omega$ and with the PMSG spinning at $\omega_{r}=200 \mathrm{rad} / \mathrm{s}$. Note a satisfying accuracy in the mechanical and electrical quantities estimated by the model. The voltage $V_{D C}$ " was properly modified by the control algorithm in order to keep the optimal ratio between the DC bus voltages $V_{D C}{ }^{\prime}$ and $V_{D C} C^{\prime \prime}$. A different test is displayed in Figure 24 in which a speed transient was forced by acting on the prime mover. More specifically, the rotational speed $\omega_{r}$ was changed from $200 \mathrm{rad} / \mathrm{s}$ to $260 \mathrm{rad} / \mathrm{s}$ while the resistive load was still kept constant. Even in this case, the model accurately predicted the behavior of the drive, both at steady-state and transient. The DC bus voltages were both affected by the speed variation, but the feedback control loops restored the reference values. A step load variation was imposed in the test of Figure 25, where the DC load was purposely doubled by switching from $T_{L}=2 \mathrm{Nm}$ to $T_{L}=4 \mathrm{Nm}$. In this case, a more remarkable difference was observed between the model and the experimental results. Finally, the effectiveness of the model to predict the balancing of the voltages across the DC bus capacitors is shown in Figure 26. Initially, the balancing algorithm described in the previous sections was inactive, and thus, the voltages at the terminals of $C_{1}$ and $C_{2}$ were significantly different. At the instant $t^{*}$, the voltage-balancing approach was activated, nullifying $V_{C 1}-V_{C 2}$. The results of Figure 26 confirm the capability of the model to accurately simulate even this critical issue of the AHUTR. Maximum percentage errors between the outputs of the SimPower System and the averaged-value model are 
summarized in Table 7, where the quantities with the suffix $\Delta$ are the errors in estimating $V_{D C}{ }^{\prime}, \omega_{r}, T_{e}$, $V_{D C}{ }^{\prime \prime}, i_{n}, V_{c 1}$, and $V_{c 2}$.

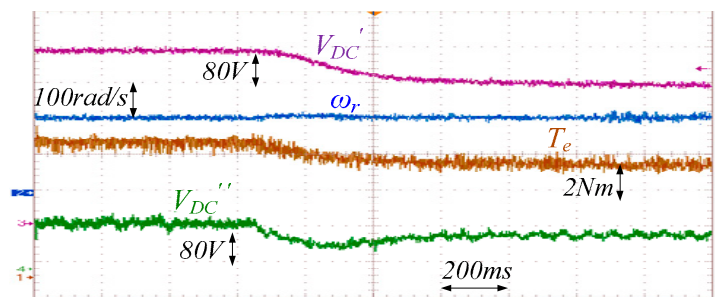

(a)

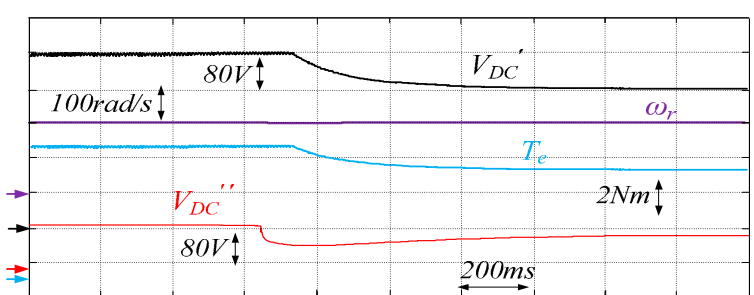

(b)

Figure 23. Voltage transient of $V_{D C^{\prime}}$ from $400 \mathrm{~V}$ to $320 \mathrm{~V}$ under a constant resistor value $R_{L}=80 \Omega$. Output voltage $V_{D C}{ }^{\prime}$, TLI DC bus voltage $V_{D C}$ ", rotor speed $\omega_{r}$, electromagnetic torque $T_{e}$. (a) Experimental results. (b) Simulation results.

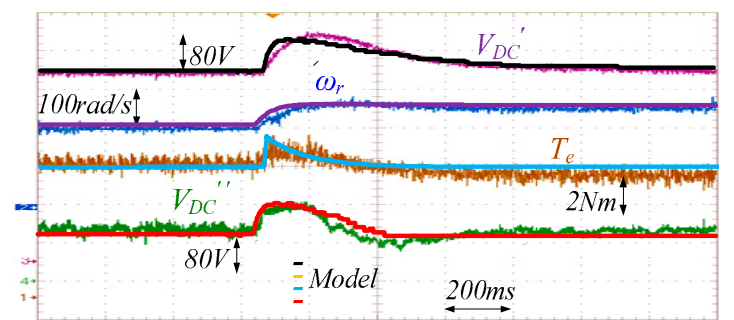

(a)

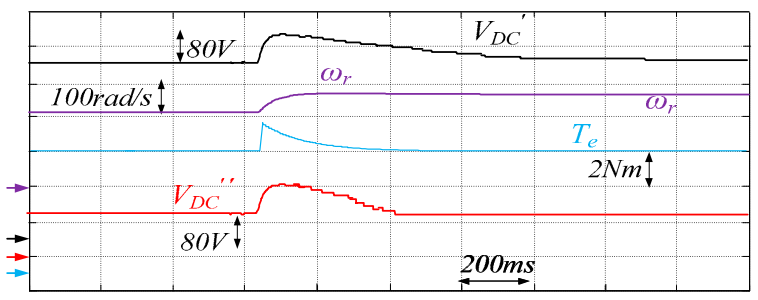

(b)

Figure 24. Speed transient from $\omega_{r}=200 \mathrm{rad} / \mathrm{s}$ to $\omega_{r}=260 \mathrm{rad} / \mathrm{s}$ under a constant resistor value $R_{L}=80 \Omega$ and $V_{D C^{\prime}}=400 \mathrm{~V}, V_{D C}{ }^{\prime \prime}=100 \mathrm{~V}$. Output voltage $V_{D C^{\prime}}$, TLI DC bus voltage $V_{D C}{ }^{\prime \prime}$, rotor speed $\omega_{r}$, electromagnetic torque $T_{e}$. (a) Experimental results. (b) Simulation results.

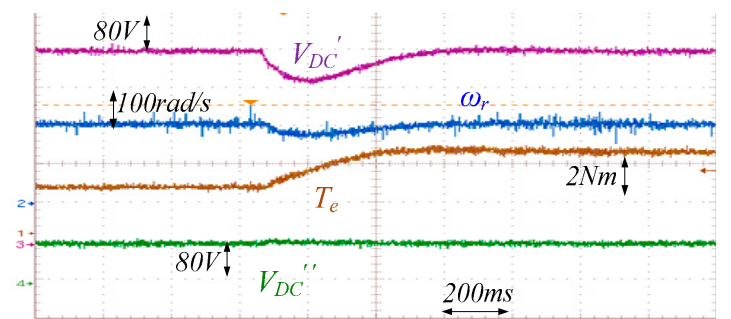

(a)

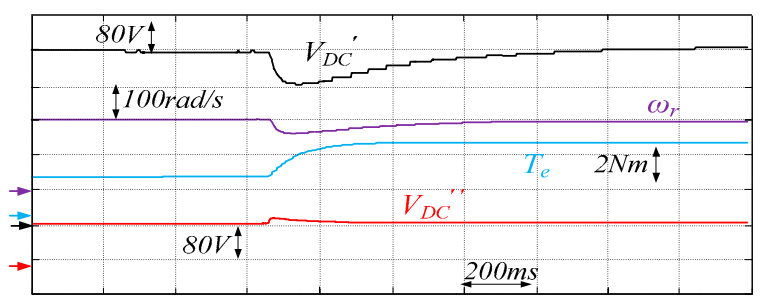

(b)

Figure 25. Load transient from $T_{L}=2 \mathrm{Nm}$ to $T_{L}=4 \mathrm{Nm}$ at $\omega_{r}=200 \mathrm{rad} / \mathrm{s}$ and $V_{D C^{\prime}}=400 \mathrm{~V}, V_{D C} C^{\prime \prime}$ $=100 \mathrm{~V}$. Output voltage $V_{D C}{ }^{\prime}$, TLI DC bus voltage $V_{D C}$ ", rotor speed $\omega_{r}$, electromagnetic torque $T_{e}$. (a) Experimental results. (b) Simulation results.

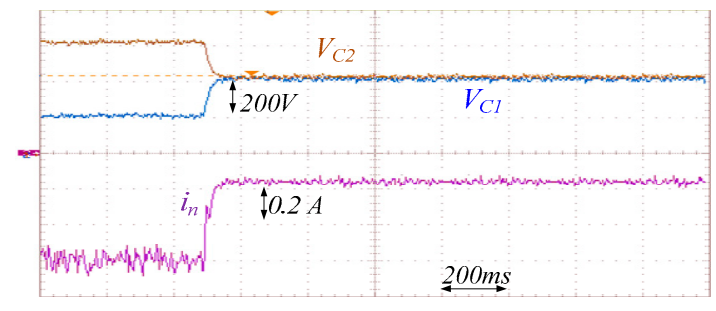

(a)

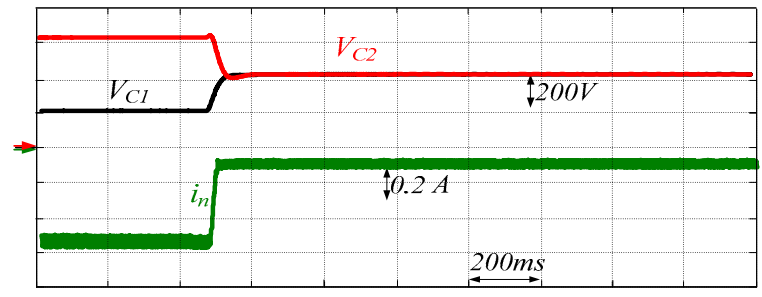

(b)

Figure 26. DC bus voltage balancing: $T_{L}=4 \mathrm{Nm}, \omega_{r}=200 \mathrm{rad} / \mathrm{s}$ and $V_{D C}{ }^{\prime}=400 \mathrm{~V}, V_{D C}{ }^{\prime \prime}=100 \mathrm{~V} . V_{c 1}$, $V_{c 2}$ and $i_{n}$. (a) Experimental results. (b) Simulation results. 
Table 7. Errors between experimental results and those obtained with the averaged-value model.

\begin{tabular}{|c|c|c|c|c|c|c|c|}
\hline Test & $\Delta V_{D C^{\prime}}(\%)$ & $\Delta \omega_{r}(\%)$ & $\Delta T_{e}(\%)$ & $\Delta V_{D C}{ }^{\prime \prime}(\%)$ & $\Delta i_{n}{ }^{\prime}(\%)$ & $\Delta V_{C 1}(\%)$ & $\Delta V_{C 2}(\%)$ \\
\hline Figure 22 & 2.2 & 1.9 & 3.7 & 4.7 & 1 & 1 & 1 \\
\hline Figure 23 & 2.1 & 2.6 & 5 & 7.7 & I & / & / \\
\hline Figure 24 & 4.5 & 4.9 & 6 & 5 & I & / & / \\
\hline Figure 25 & / & l & / & / & 6.6 & 10 & 4 \\
\hline
\end{tabular}

\section{Conclusions}

The asymmetrical hybrid unidirectional T-type rectifier is more efficient than a conventional PWM rectifier, mainly due to line frequency operation of the main converter, a T-type rectifier. However, it features a more complex structure composed of three main components, namely a TTR, a TLI, and an open winding electric machine, all interacting. The development of an accurate averaged-value mathematical model of the AHUTR topology aimed to optimally design control and management algorithms has been faced in the paper. Simulations and experimental results show that the proposed model is able to reproduce the static and dynamic behavior of the AHUTR with good accuracy. Furthermore, the obtained mathematical representation made a fast analysis of the system during TTR DC bus voltage unbalance operations possible. This has been exploited to design an active balancing system acting on the TLI side-a task which would be time-consuming with circuit-oriented simulator models. Furthermore, the averaged-value model has been used to define the entire AHTUR control and management system tasked to deal with efficiency maximization, input power factor control, TTR DC bus capacitor voltage balance, and the control of TLI floating DC bus voltage.

Author Contributions: This work was carried out in collaboration between all authors. S.F., G.S. and A.T. designed the study, wrote the manuscript and analyzed simulations and experimental results. A.S. undertook all of the experimental measurements.

Conflicts of Interest: The authors declare no conflict of interest.

\section{References}

1. Kaarthik, R.S.; Gopakumar, K.; Mathey, J.; Underland, T. Medium Voltage Drive for Induction Machine with Multilevel Dodecagon Voltage Space Vectors with Symmetric Triangles. IEEE Trans. Ind. Electron. 2015, 62, 79-87. [CrossRef]

2. Kouro, S.; Malinowski, M.; Gopakumar, K.; Pou, J.; Franquelo, L.G.; Wu, B.; Rodriguez, J.; Perez, M.A.; Leon, J.I. Recent Advances and Industrial Applications of Multilevel Converters. IEEE Trans. Ind. Electron. 2010, 57, 2553-2580. [CrossRef]

3. De Caro, S.; Foti, S.; Scimone, T.; Testa, A.; Cacciato, M.; Scarcella, G.; Scelba, G. THD and efficiency improvement in multi-level inverters through an open end winding configuration. In Proceedings of the IEEE 2016 Energy Conversion Congress and Expo, Milwaukee, WI, USA, 18-22 September 2016; pp. 1-7.

4. Edpuganti, A.; Rathore, A. A Survey of Low Switching Frequency Modulation Techniques for Medium-Voltage Multilevel Converters. IEEE Trans. Ind. Appl. 2015, 51, 4212-4228. [CrossRef]

5. Mondal, G.; Sivakumar, K.; Ramchand, R.; Gopakumar, K.; Levi, E. A Dual Seven-Level Inverter Supply for an Open-End Winding Induction Motor Drive. IEEE Trans. Ind. Electron. 2009, 56, 1665-1673. [CrossRef]

6. Wang, Y.; Panda, D.; Lipo, T.A.; Pan, D. Open-Winding Power Conversion Systems Fed by Half-Controlled Converters. IEEE Trans. on Power Electron. 2013, 28, 2427-2436. [CrossRef]

7. Mohapatra, K.K.; Gopakumar, K.; Somasekhar, V.T.; Umanand, L. A Harmonic Elimination and Suppression Scheme for an Open-End Winding Induction Motor Drive. IEEE Trans. Ind. Electron. 2003, 50, 1187-1198. [CrossRef]

8. Kawabata, Y.; Nasu, M.; Nomoto, T.; Ejiogu, E.C.; Kawabata, T. High-efficiency and low acoustic noise drive system using open-winding AC motor and two space-vector-modulated inverters. IEEE Trans. Ind. Electron. 2002, 49, 783-789. [CrossRef]

9. Sivakumar, K.; Das, A.; Ramchand, R.; Patel, C.; Gopakumar, K. A hybrid multilevel inverter topology for an open-end winding induction-motor drive using two-level inverters in series with a capacitor-fed $\mathrm{H}$ - bridge cell. IEEE Trans. Ind. Electron. 2010, 57, 3707-3714. [CrossRef] 
10. Somasekhar, V.T.; Gopakumar, K.; Bajiu, M.R.; Mohapatra, K.K.; Umanand, L. A multilevel inverter system for an inductor motor with open-end windings. IEEE Trans. Ind. Electron. 2015, 52, 824-836. [CrossRef]

11. Edpuganti, A.; Rathore, A.K. Optimal Pulsewidth Modulation for Common-Mode Voltage Elimination Scheme of Medium-Voltage Modular Multilevel Converter-Fed Open-End Stator Winding Induction Motor Drives. IEEE Trans. Ind. Electron. 2017, 64, 848-856. [CrossRef]

12. Foti, S.; Testa, A.; Scelba, G.; De Caro, S.; Cacciato, M.; Scarcella, G.; Scimone, T. An Open-End Winding Motor Approach to Mitigate the Phase Voltage Distortion on Multilevel Inverters. IEEE Trans. Power Electron. 2018, 33, 2404-2416. [CrossRef]

13. Foti, S.; Testa, A.; Scelba, G.; Sabatini, V.; Lidozzi, A.; Solero, L. A symmetrical hybrid unidirectional T-type rectifier for high-speed gen-set applications. In Proceedings of the IEEE Energy Conversion Congress and Expo, Cincinnati, OH, USA, 1-5 October 2017; pp. 4887-4893.

14. Foti, S.; De Caro, S.; Scelba, G.; Scimone, T.; Testa, A.; Cacciato, M.; Scarcella, G. An Optimal Current Control Strategy for Asymmetrical Hybrid Multilevel Inverters. IEEE Trans. Ind. Appl. 2018, 54, 4425-4436. [CrossRef]

15. Mengoni, M.; Amerise, A.; Zarri, L.; Tani, A.; Serra, G.; Casadei, D. Control Scheme for Open-Ended Induction Motor Drives with a Floating Capacitor Bridge Over a Wide Speed Range. Trans. Ind. Applications 2017, 53, 4504-4514. [CrossRef]

16. Pan, Z.; Peng, F.Z.; Corzine, K.A.; Stefanovic, V.R.; Leuthen, J.M.; Gataric, S. Voltage balancing control of diode-clamped multilevel rectifier/inverter systems. IEEE Trans. Ind. Applications 2005, 41, 1698-1706. [CrossRef]

17. Yan, G.; Duan, S.; Zhao, S.; Li, G.; Wu, W.; Li, H. Research on the mechanism of neutral-point voltage fluctuation and capacitor voltage balancing control strategy of three-phase three-level T-type inverter. J. Electr. Eng. Technol. 2017, 12, 2227-2236.

18. Zhang, Y.; Li, J.; Li, X.; Cao, Y.; Sumner, M.; Xia, C. A Method for the Suppression of Fluctuations in the Neutral-Point Potential of a Three-Level NPC Inverter with a Capacitor-Voltage Loop. IEEE Trans. Power Electron. 2017, 32, 825-836. [CrossRef] 